Article

\title{
Impacts of Land Management on the Resilience of Mediterranean Dry Forests to Fire
}

\author{
Matteo Jucker Riva ${ }^{1,2, *}$, Hanspeter Liniger ${ }^{2}$, Alejandro Valdecantos ${ }^{3}$ and Gudrun Schwilch ${ }^{2}$ \\ 1 Institute of Integrative Geography, University of Bern, Bern 3012, Switzerland \\ 2 Centre for Development and Environment (CDE), University of Bern, Bern 3012, Switzerland; \\ hanspeter.liniger@cde.unibe.ch (H.L.); Gudrun.Schwilch@cde.unibe.ch (G.S.) \\ 3 Mediterranean Centre for Environmental Studies (Foundation CEAM), Valencia 46980, Spain; \\ a.valdecantos@ua.es \\ * Correspondence: matteo.jucker@cde.unibe.ch; Tel.: +41-76-559-0724
}

Academic Editor: Vincenzo Torretta

Received: 26 July 2016; Accepted: 22 September 2016; Published: 29 September 2016

\begin{abstract}
Wildfires have always been a part of the history of Mediterranean forests. However, forests are not always certain to regenerate after a wildfire. Whether they do depends on many factors, some of which may be influenced by land management activities. Failure to regenerate will cause a regime shift in the ecosystem, reducing the provision of ecosystem services and ultimately leading to desertification. How can we increase the resilience of Mediterranean forests to fire? Our approach to answering this question was twofold: first, we reviewed the literature to investigate chains of processes that allowed forests to regenerate (which we label Regeneration Mechanisms, or RMs); and second, we assessed the impact of selected management practices documented in the WOCAT database on these RMs. For the assessment, we evaluated the relation between the benefits and disadvantages of the land management practices on the one hand, and the hindering and supporting factors of the RMs on the other. We identified three distinct RMs that enable Mediterranean forests to recover, as well as the time frame before and after a fire in which they are at work, and factors that can hinder or support resilience. The three RMs enabling a forest to regenerate after a fire consist of regeneration (1) from a seed bank; (2) from resprouting individuals; and (3) from unburned plants that escaped the fire. Management practices were grouped into four categories: (1) fuel breaks; (2) fuel management; (3) afforestation; and (4) mulching. We assessed how and under what conditions land management modifies the ecosystem's resilience. The results show that land management influences resilience by interacting with resilience mechanisms before and after the fire, and not just by modifying the fire regime. Our analysis demonstrates a need for adaptive-i.e., context- and time-specific — management strategies.
\end{abstract}

Keywords: resilience; land management; wildfire; Mediterranean dry forest

\section{Introduction}

Dry Mediterranean ecosystems are said to be particularly resilient to fire due to their long history of exposure to this type of disturbance. Many of the plant species found in Mediterranean forests and shrublands show some degree of adaptation to fire and even rely on fire events to complete certain stages in their life cycle [1]. However, some previously forested areas in Mediterranean drylands have experienced a regime shift following a wildfire. While the most evident trigger of such a regime shift is a change in the fire regime (i.e., frequency and/or intensity of fire), the root causes are systemic and linked to multiple factors that interact within the local ecosystem, including climate, soil properties, land use, land use history, and others [2]. 
According to the concept of "ecological resilience" [3], an ecosystem can be considered resilient if it is able to recover its composition, structure, and main functions following a disturbance. Thus, we can label a forest as resilient if, after a disturbance, it is able to recover its previous vegetation structure (e.g., a tree layer and a shrub/ground layer), and if the regenerated community is composed of the same set of species. In this way, the regeneration of trees that constituted the pre-disturbance canopy is not only the most visible display of resilience, but also the main concrete process that fosters resilience [4]. The recovery of the vegetation depends on specific chains of physical processes that take place before, during, or after the disturbance. We refer to them as Regeneration Mechanisms, or RMs.

Land management practices in Mediterranean forests are generally focused on reducing fire occurrence or on mitigating its impacts. However, these interventions interact with all components of the ecosystem: vegetation, soil, fauna, and human action. There is little research on the effectiveness of these management practices on canopy regeneration due to the long time span needed for assessments as well as the variability in time and space of forest ecosystems, fire events, and management approaches. Most of the available literature focuses on changes in the fire regime. Nevertheless, land management practices are a fundamental tool for controlling the evolution of the forest; therefore, assessing their impacts is an important means of "learning by doing", which is essential to improving the sustainability and management of our ecosystems [5]. Documenting how management is implemented on the ground, and studying the direct and indirect impacts on the ecosystem is crucial if we want to increase the resilience of Mediterranean forest ecosystems.

In this paper, we begin by reviewing the scientific literature on RMs in Mediterranean forest ecosystems, which we believe lays the groundwork for subsequent resilience assessments and evidence-based management decisions. We then present the results of land managers' and other experts' assessments of systemic interactions between land management practices and forest RMs. These assessments and the corresponding analytical framework can enable forest managers to better understand the vulnerabilities of their own specific system, and can enable researchers to identify knowledge gaps in our scientific understanding of the resilience of real-world forest ecosystems.

\section{Materials and Methods}

\subsection{Identification of RMs}

We began our investigation of the impact of land management on the resilience of Mediterranean forests to fire with the following questions: What processes are involved in the recovery of forests after fire? What factors could hinder or support these processes?

These questions led us to structure the concept of RMs as the chains of processes that enable forests to recover after a fire event.

RMs are characterized by the following properties:

- Processes involved: biological processes that enable the forest to recover and constitute the actual RM. One example is the constitution of a seed bank prior to the fire.

- Preparation period: the time needed before a fire for the RM to become effective and to enable forest regeneration after the disturbance. For example, plant recolonization from a seed bank requires that the plant had time to reach maturity before the fire event; in the case of Pinus halepensis, this takes 15 to 20 years [6].

- Effectiveness period: the time span after the fire event during which the RM is effective, from the appearance of the first signs of recovery to the time when no further recovery may be expected. For example, seeder species are likely to germinate in the next wet season following a fire [7] but no longer than two years after the fire.

- Hindering and supporting factors: factors that may reduce (hindering factors) or increase (supporting factors) the RM's effectiveness. For example, frequent fires will reduce the capacity of plants to resprout, preventing regrowth of forest resprouter species [8]. 
To characterize the RMs of Mediterranean dry forests, we analyzed scientific literature published after 2000 and available through Web of Science and ScienceDirect in April 2014. We selected literature related to three different study realms: (1) direct observations of fire impact or of vegetation recovery after fire, using the keywords "fire", "forest", and "Mediterranean", and screening for studies that investigated recovery after real-world fire events; (2) studies (including reviews and modelling studies) on functional traits related to recovery after fire using the keywords "ecology", "fire", "traits", and excluding the papers not related to the vegetation of Mediterranean forests; and (3) articles providing information on the physiology of key Mediterranean species. The articles found during research for points (2) and (3), of the articles found with the first research were integrated with the information provided by the plant trait database for Mediterranean Basin species [6], and following a "snowball" methodology, with articles published before the year 2000, when knowledge gaps emerged.

For categories (1) and (3) we selected only articles related to the vegetation of the Mediterranean basin, while for category (2) we also included articles on ecosystems similar to but located outside the Mediterranean basin (i.e., California, Australia, South Africa).

This investigation resulted in a selection of 126 papers. By reviewing their abstracts we reduced this to 41 papers that provided useful information for characterizing RMs and their properties. These were included in the analysis that constitutes the first part of this paper.

Finally, to evaluate the impacts of land management on the resilience of Mediterranean forests to fire, we investigated how different management practices affect these RMs.

\subsection{Data on Land Management Practices}

The World Overview of Conservation Approaches and Technologies (WOCAT) database contains information on sustainable land management practices from around the world that have been documented in a standardized and scientific manner [9-11]. Each assessment refers to a specific land management practice implementation.

In particular, information about benefits and disadvantages of land management practices is derived from a semi-quantitative assessment based on consultation with a diverse group of stakeholders, combined, wherever possible, with scientific data and observations [12].

We selected the land management practices for this study according to three criteria that, taken together, define Mediterranean forests: (1) the land use type is forest/woodland; (2) the agro-climatic zone is sub-humid to semiarid; and (3) the practice is applied in a Mediterranean country (Europe including Portugal, and North Africa). The land management practices were then grouped according to their main objectives: fuel breaks (prevention), fuel management (prevention), reforestation (rehabilitation), and soil protection (mitigation).

\subsection{Assessing the Impact of Management Practices on RMs}

First, we established a link between the indicators of ecological benefits and disadvantages used in the WOCAT Technology Questionnaire and the hindering and supporting factors of the three RMs. The relation between the benefits and disadvantages of the land management practices and the hindering and supporting factors of each RM was classified as "direct/strong" when the two referred to the same process or were directly related (e.g., "increase in soil moisture" in the WOCAT assessment with "high water and nutrient content" as supporting factor); it was classified as "indirect/weak" when the benefit/disadvantage could influence the hindering or supporting process as a side effect (e.g., "Increased soil cover" in the WOCAT assessment with "high water and nutrient content" as supporting factor).

Moreover, the relation was classified as "positive" when the benefit/disadvantage reinforced the hindering/supporting process, or "negative" when undermining it. All the relations were inserted into a matrix that served as base for the actual evaluation.

On this basis, we were able to determine how the land management practices influence the hindering and supporting factors of each regeneration mechanism, thus identifying hindering and 
supporting interactions between land management and the resilience of Mediterranean forest to fire. In doing so, we also considered differences between land management practices belonging to the same group.

\section{Results}

\subsection{RM1: Forest Regenerates from a Seed Bank}

\subsubsection{Processes Involved}

Post-fire regeneration from a seed bank refers to forest regrowth from seeds produced before the fire event and left in the soil or the canopy. This RM includes multiple processes. For the forest to regenerate after a fire, plants must first reach sexual maturity and produce viable seeds, which need to be stored in the canopy or in the soil, creating a seed bank. The seeds then have to survive the fire, germinate, and produce seedlings that survive their juvenile stage and reach maturity again (Figure 1).

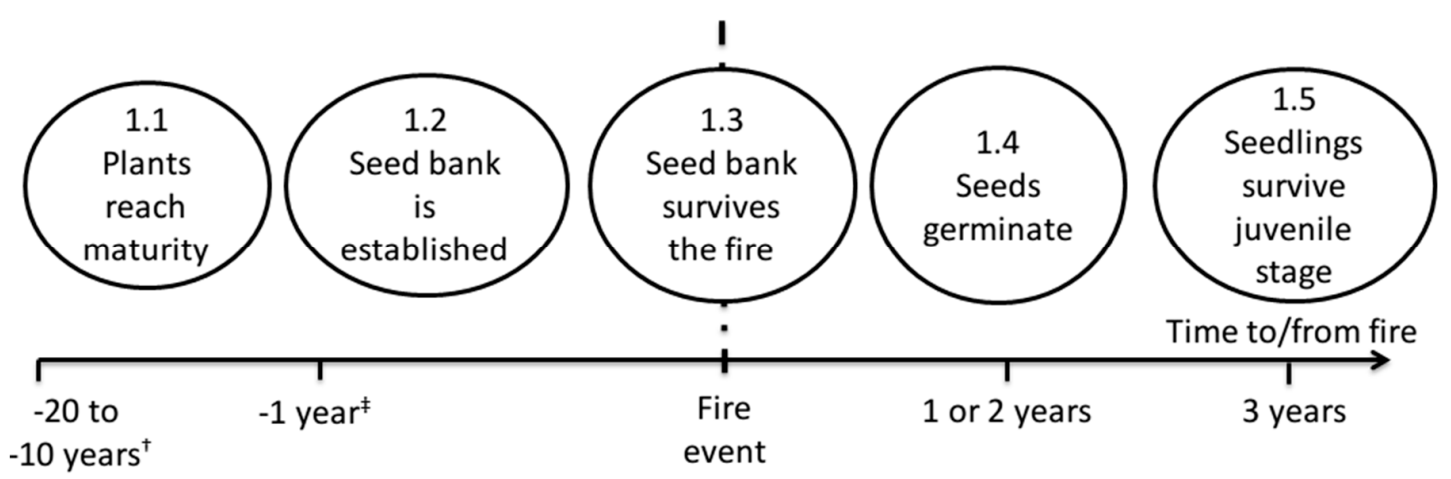

Figure 1. Processes involved in forest regeneration from a seed bank (RM1) ${ }^{\dagger}$ Time needed for trees to reach maturity. Shrubs take between 5 and 10 years (see Table 1 ). $\ddagger$ For transient/ground seed banks. Seeds can remain in the canopy for up to 50 years.

Post-fire regeneration from a seed bank refers to forest regrowth from seeds produced before the fire event and left in the soil or the canopy. This RM includes multiple processes. For the forest to regenerate after a fire, plants must first reach sexual maturity and produce viable seeds, which need to be stored in the canopy or in the soil, creating a seed bank. The seeds then have to survive the fire, germinate, and produce seedlings that survive their juvenile stage and reach maturity again.

Even if most plants produce seeds, a reduced number of species only recover from seeds while the rest combine this strategy with resprouting organs. [13]. The traits that characterize a so-called "seeder plant" include a high production of seeds, mechanisms for seed dispersal, and a high germination rate [14].

Some of the common seeders of the Mediterranean area appear to have adapted specifically to fire: their seed bank is protected in the canopy (e.g., in cones) rather than in the soil, and seed dispersal is triggered by heat, increasing the chances of successful germination [15]. Table 1 presents common seeder species in the Mediterranean basin.

Seeder species are often highly flammable and, especially when the germination is stimulated by heat, they tend to form a highly dense canopy structure, which increases the risk of intense fires. 
Table 1. Common seeder species in the Mediterranean basin and their traits related to RM1.

\begin{tabular}{|c|c|c|c|c|c|c|}
\hline Species & $\begin{array}{c}\text { Longevity } \\
\text { of Seed } \\
\text { Bank }\end{array}$ & $\begin{array}{c}\text { Heat-Stimulated } \\
\text { Germination }^{\dagger}\end{array}$ & $\begin{array}{c}\text { Post-Fire } \\
\text { Seedling } \\
\text { Emergence }\end{array}$ & $\begin{array}{c}\text { Seedling } \\
\text { Survival } \\
\text { after First } \\
\text { Summer } \S\end{array}$ & $\begin{array}{c}\text { Type of } \\
\text { Seed } \\
\text { Bank }\end{array}$ & $\begin{array}{l}\text { Age of } \\
\text { Maturity } \\
\text { (years) }\end{array}$ \\
\hline Cistus salvifolius & $>1$ year ${ }^{+t}$ & + & high & high & soil & $1-2$ \\
\hline Erica umbellata & $<1$ year & 0 & yes & high & soil & $<5$ \\
\hline Cupressus sempervirens & $>15$ years & no data & yes & high & aerial & 6 \\
\hline Pinus halepensis & $>5$ years & $0 /+$ & high & high & aerial & $10-20$ \\
\hline Pinus brutia & $<1$ year & $-/ 0$ & high & high & aerial & 9 \\
\hline Rosmarinus officinalis & $<1$ year & 0 & yes & high & soil & $4-10$ \\
\hline Thymus vulgaris & $<1$ year & 0 & yes & no data & soil & $<5$ \\
\hline Ulex parviflorus & $>1$ year & + & high & high & soil & 2 \\
\hline
\end{tabular}

Sources: $[6,16,17] ;{ }^{\dagger},+:$ positive effect of heat on germination; 0 : no effect; - : negative effect; ${ }^{\ddagger}$ yes: seedlings have been observed after a fire but no quantitative data is available; high: the number of seedlings emerging after the fire is higher than the number of individuals before the fire; $\$$ high: more than $25 \%$ of seedlings survive the first summer; ' soil: once the seeds are fully developed, they immediately detach themselves from the plant; aerial: seeds remain in the canopy after reaching full development; ${ }^{\mathbb{I I}}$ time needed for new seedlings to reach sexual maturity and start producing seeds; ${ }^{+\dagger}$ Indicates a non-transient seed bank; ${ }^{\ddagger \ddagger}$ Indicates a transient seed bank.

\subsubsection{Preparation and Effectiveness Periods}

For this RM to function, the vegetation has to produce seeds before the fire event. The length of the preparation period depends on the time required for the plants to reach sexual maturity and constitute a seed bank. The age of maturity depends primarily on the plant genotype and can vary between one year (Cistus salvifolius) and 15-20 years (Pinus halepensis) (Table 1). However, environmental conditions and events in the plants' life history can delay or even prevent this process [18]. Once the fire event has occurred, the time it takes until the vegetation can begin to recover depends on two interacting processes: (1) Seed persistence, defined as the period during which a seed will be able to germinate; and (2) dormancy, or the period during which a seed will not germinate despite being alive and able to grow [19]. Generally, the more a seed is exposed (to climatic variation, predation by animals, chemicals, etc.), the shorter it will survive and be able to germinate.

Dormancy can be influenced by genetics, environmental factors (the seed germinates when light, temperature, humidity, or nutrient conditions are above a certain threshold), or a combination of the two [19]. The high temperatures of fire events seem to break dormancy in certain species (see "Heat-stimulated germination", Table 1), making them particularly efficient in recovering from fire [2].

Scientists classify seed banks into transient (if seeds survive less than a year) and persistent (seeds survive more than a year) (see "Seed bank longevity", Table 1). A transient seed bank experiences substantial seasonal fluctuations between autumn and spring [17].

Seasonal climatic variation, seed persistence, and dormancy combine to determine an optimal window for post-fire seed germination. It is difficult to obtain quantitative information about this window for individual Mediterranean plant species, but Quintana et al. (2004) suggest, based on empirical measurements, that this optimal window might be pinpointed as the next wet season (i.e., first autumn, winter, and spring) after the fire, and extend to no more than the next two years [20].

\subsubsection{Hindering and Supporting Factors}

The most widely examined hindering factor by far in the ecological literature is the fire regime [21], constituted by fire frequency and fire severity. The interval between two fires (which determines the fire frequency) has to be longer than the time the plants take to reach maturity and produce seeds, otherwise there will be no seeds to start the recovery process anew. Fire severity or the amount of biomass that is burned during a fire event [22] influences seed mortality both in the soil and in the canopy.

Plant development and seed production can be affected by poor environmental conditions, and especially by water scarcity [18]. Besides climatic variations, topography and soil type will reduce the 
soil's water holding capacity, moisture, and stability. Once the seeds have reached full development, they have to survive the fire event to enable regeneration.

In the case of a transient seed bank, the timing of a fire event in relation to the flowering period is crucial: recovery is less likely if a fire occurs during flowering (normally spring) or late in the season (autumn), as this will drastically reduce the amount of fertile seeds [23]. In a soil seed bank, sheltering from the weather and animal predation appears crucial to ensure seed survival. Accordingly, soil erosion can be considered a hindering factor, whereas the presence of organic litter and mosses can be considered a supporting factor. Animal predation is another major factor of seed mortality. The relevance of this process depends on the types of seeds and animals, but also on the exposure of seeds: it is negatively correlated to burial depth [24].

Germination in post-fire conditions depends, first of all, on water availability. Thus, meteorological anomalies and especially dry spells in autumn and winter can heavily harm regeneration. Fire-stimulated germination (by heat or smoke) increases the chances of seedling survival, because new seedlings will emerge before other plants and will not have to compete for resources. However, if germination occurs in hostile environmental conditions (i.e., during a dry spell), the whole recovery process may fail, leading to a regime shift. Seeder species communities affected by (late) winter fires are especially sensitive to collapse, as germinated seedlings have not produced well-developed belowground systems to overcome the expected summer drought.

While the impact of ashes on germination is controversial, the presence of litter-both pre-fire litter or mosses and burned residues-is important for germination, as it increases soil humidity and nutrients, reduces erosion, and protects seedlings [2].

After germination, plants go through a period of high vulnerability to scarcity of water and nutrients, which is generally considered to last three years. In a post-fire situation, competing plants include grasses and resprouting species that take less time to regrow than seedlings [20]. Intra-specific competition may also occur several years after the fire in case of massive post-fire recruitment but these situations only affect the individual and not the population level.

\subsection{RM2: Forest Regenerates from Resprouting Individuals}

\subsubsection{Preparation and Effectiveness Periods}

Instead of working with RM1 and creating seeds that survive a fire, some plants have the ability to regrow stems, branches, and leaves from unburned protected organs. RM2, which builds on this ability, includes the processes of such "resprouter plants" establishing themselves in the area, developing a bud bank (also soil or aerial) and protected organs, storing nutrients and water to survive the fire, and regrowing their burned tissues (Figure 2).

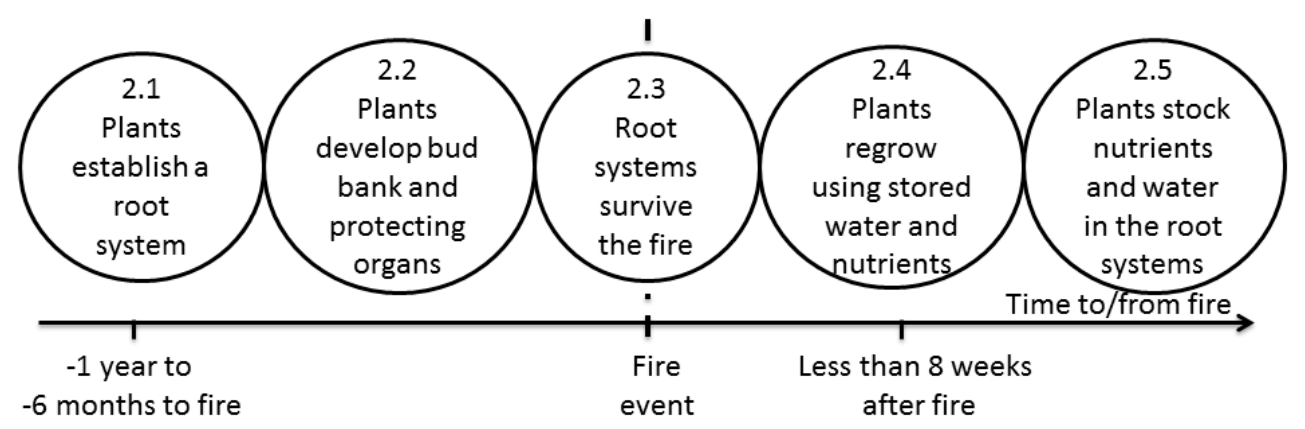

Figure 2. Processes involved in forest regeneration from resprouting plants (RM2).

We included establishment of individuals in the RM because this process is much more difficult for resprouters than for seeder species under natural conditions. In fact, species that work with RM2 are normally characterized by lower seed production (and even years without production at all) and 
a low germination rate [25]. This influences the structure of the forest where resprouter species are dominant, characterized by large trees of varying heights and shapes as well as a high variety of species. Resprouters in Mediterranean forest ecosystems are often associated with older, less disturbed forest stands that tend to be highly resistant to fire [26].

The following traits enable plants to use RM2: a bud reserve from where new sprouts will grow; mechanisms to protect these bud banks, such as thick bark, height, or an underground bud bank; a deep and thick root system; and the ability to store nutrients and water in the roots or stem. Scientists have identified a variety of resprouting strategies that differ mainly in the location of new buds, but also include various strategies for bud protection and nutrient storage. Table 2 presents common Mediterranean basin species that rely on RM2.

Table 2. Common resprouter species of the Mediterranean basin and the location of their buds.

\begin{tabular}{cc}
\hline Plant Name & Bud Location \\
\hline Acer campestre & root and crown \\
Arbutus unedo & root and crown \\
Buxus sempervirens & non specified \\
Ceratonia silique & branches \\
Daphne gnidium & stem buds \\
Fraxinus ornus & roots \\
Juniperus oxicedrus & root and crown \\
Laurus nobilis & non specified \\
Phyllirea angustifolia & non specified \\
Pistacia lentiscus & roots \\
Prunus spinosa & root and crown \\
Quercus ilex & lignotuber \\
Quercus suber & lignotuber \\
Rhamnus alaternus & root and crown \\
\hline & Sources: [6,27].
\end{tabular}

\subsubsection{Preparation and Effectiveness Periods}

The length of the preparation time required for this RM to work depends, first, on the time needed for seed arrival and germination and, second, on the ability of the plant to develop a root system and organs it needs to survive the fire and accumulate resources for post-fire growth (e.g., a bud bank and bark or some other protection system).

The time resprouter species require to establish a consistent presence in forests is very difficult to forecast because it depends on environmental factors, genetic factors, and contingent events in the life history each individual [14,28]. In general, the drier and less stable the climate, and the less fertile the soil, the more difficult it is for seeds of resprouter species to germinate and reach maturity [25].

Depending on the plant's strategy, its ability to resprout will reach its maximum before or during maturity and will then decrease as the plant undergoes senescence [29]. However, post-fire resprouting capacity seems to appear a few months after root establishment, as has been observed for Quercus ilex. (personal observation). At the level of the individual plant, resprouting is a dichotomous event, in the sense that after a fire, the plant either resprouts or dies [30]. If it resprouts, this happens immediately after the fire: Malanson and Trabaud (1988) [31] suggest that if no resprouts have been observed during the first eight weeks after the fire, the individual is dead.

At the level of the forest stand, locally unfavourable environmental conditions or high fire intensity might delay this RM (or the plants' "resprouting vigour", [31]). However, the negative impact of these factors appears to be relevant only in the first months to years after a fire. Empirical studies conclude that differences even out within three years after the event [32]. 


\subsubsection{Hindering and Supporting Processes}

Compared to seed regeneration (RM1), resprouting (RM2) is considered a much more secure and rapid path to recovery with fewer hindering factors [13]. However, the presence of resprouting plants can be greatly reduced by human activities: logging, uprooting, and heavy grazing can cause plants to die, and the typically low recruitment rate of resprouter species will limit or prevent regeneration once an individual is dead [29]. Furthermore, seeds of resprouting species are much more sensitive to unfavourable environmental conditions than those of seeder species, and may fail to germinate if, for example, the rainfall regime is unstable and soil fertility is low.

Once a resprouter plant is established, it has to develop the underground and above-ground organs (depending on bud location, see Table 2). Soil depth is crucial at this stage, as it determines the plant's root development and how well its underground bud banks are sheltered [33]. Non-structural carbohydrates are the nutrients that plants need most in order to resprout. The amount stored in the plants is subjected to considerable seasonal variations. Studies based on prescribed burning suggest that fires have a stronger negative impact on resprouting if they occur in the later seasons, when nutrient reserves are lower [30]. Coppicing is a traditional way of exploiting the valuable wood of resprouter trees (in particular Quercus ilex and Q. pubescens), which involves cutting back branches or parts of the trunks of trees and allowing them to resprout. This technique appears to stimulate the resprouting capacity of the plant, also increasing its post-fire resprouting vigour [34].

During the fire event, fire intensity, or the energy released during the fire [22], is the main factor inducing mortality in resprouter plants, as high temperatures can burn the bud bank and damage the protected aerial buds and the root system [35]. Another important hindering factor is plant size at the time of the fire. Stem size in particular is correlated to root system development. The bigger the stem and root system, the greater the chances of survival after a fire [30].

After a fire, plants have to rely on stored water and nutrients until they regrow leaves and return to photosynthesis. The relationship between the use of stored energy and photosynthesis varies among species and depends on their resprouting strategy [29]. Regrowth and resprouting vigour may be delayed during the first years after a fire by factors such as reduced water availability-which, in turn, may be the result of aspect, competition, or seasonality [31].

If no fire occurs during a long enough time, resprouters may reach the senescent stage and lose their capacity to resprout. This can also prevent their recovery from a subsequent fire event [29].

\subsection{RM3: Forest Regenerates from Unburned Plants or Patches}

\subsubsection{Processes Involved}

If the vegetation in a burned area is unable to resprout or to recover from seeds after a fire, recovery will be driven by unburned vegetation. This RM has been referred to as "indirect regeneration" [26] or "recolonization" [13], as it does not involve the individuals directly affected by the fire nor their seeds, but relies on those plants that escape the fire or grow outside its boundaries. While this RM can restore the pre-fire vegetation structure (i.e., shrubland or forest), it may induce important changes in the species composition, especially if the canopy consists of heterogeneous vegetation patches. Moreover, while this RM3 is likely to be active in most burnt areas, as it takes time for seeds to spread in the burned area and germinate, RM3 will only be dominant if RMs 1 and 2 fail, and only in the case of fires where the distance from the boundaries or unburned patches to the core of the burned area is compatible with the dispersion mechanisms, distances, and life cycles of the species involved.

RM3 includes the processes of plants escaping the fire, producing seeds, the seeds being dispersed across the burned area, and finally germination (Figure 3).

Only a few plants rely mainly on this RM: those that combine low or no resprouting capacity and low seed survival, such as Juniperus oxicedrus and Pinus brutia. Plant traits that are relevant to this particular RM include: adaptation to facilitate dispersal by wind or animals; bigger size that increases chances of seed dispersal by wind/birds/insects and the number of seeds produced; and the presence 
of a fleshy fruit protecting seeds. RM3 thus generally favours seeder species. Table 3 presents common species of the Mediterranean Basin and their traits related to RM3.

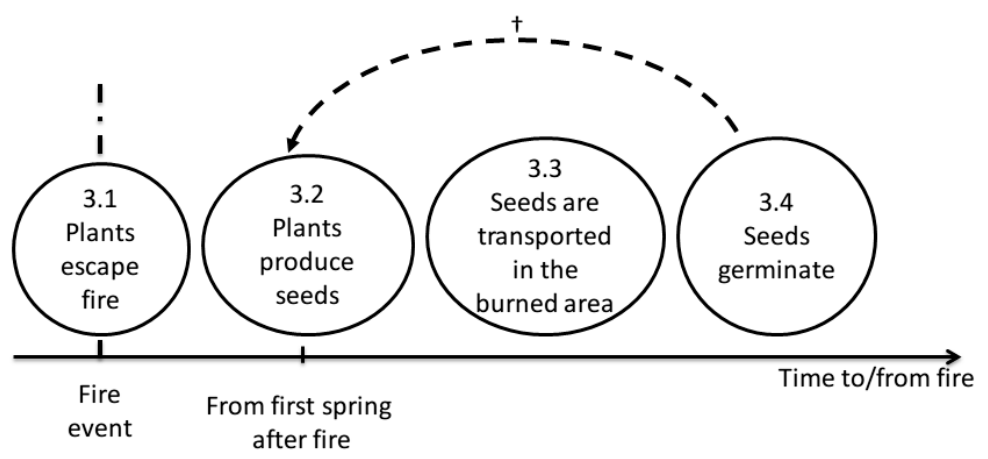

Figure 3. Processes involved in forest regeneration from unburned plants (RM3). ${ }^{+}$The arrow indicates that the process of seed creation transport and germination must be repeated several times, for the RM to be effective at the landscape scale.

Table 3. Common species of the Mediterranean Basin and traits related to forest regeneration from unburned plants (RM3).

\begin{tabular}{cccc}
\hline Plant Species & Average Height $(\mathbf{m})$ & $\begin{array}{c}\text { Dispersal Unit } \\
\text { (Propagule) }\end{array}$ & Dispersal Mode (Vector) \\
\hline Arbutus unedo & 3 & fruit & internal animal transport \\
Buxus semperivirens & 2.5 & seed & hoarding animals or fruit explosion \\
Ceratonia siliqua & 15 & fruit & internal animal transport \\
Daphne gnidium & 1.5 & fruit & internal animal transport \\
Erica umbellata & 0.6 & seed & wind \\
Fraxinus onus & 10 & fruit & wind or water \\
Juniperus oxicedrus & 10 & fruit & internal animal transport or gravity \\
Phyllirea angustifolia & 1.7 & fruit & internal animal transport \\
Pinus brutia & 25 & seed & wind \\
Pinus halepensis & 20 & seed & wind \\
Pinus nigra & 30 & seed & wind \\
Pistacia lentiscus & 2 & fruit & internal animal transport \\
Prunus spinosa & 2 & fruit & internal animal transport \\
Quercus coccifera & 2 & fruit & hoarding animals \\
Quercus faginea & 20 & fruit & hoarding animals \\
Quercus ilex & 15 & fruit & hoarding animals \\
Quercus suber & 15 & fruit & hoarding animals \\
\hline
\end{tabular}

\subsubsection{Preparation and Effectiveness Periods}

RM3 relies only on vegetation existing prior to the fire. Accordingly, the preparation period cannot be adequately defined. At the individual level, however, plants have lower chances of survival at the seedling stage and greater chances when they are fully grown and equipped with a thick bark and deep root system [36]. Thus, although not a necessity, the presence of mature plants will increase this regeneration mechanism's effectiveness and speed (Table 1). Moreover, mature or bigger plants tend to produce a higher number of seeds.

Given that RM3 relies on the ability of unburned plants or patches to produce seeds that are then dispersed across the burned area, the regeneration process can begin almost immediately after the fire, with the first seed dispersal event. However, it may take a very long time for the entire burned area to be covered, depending on the size and shape of the burned patch and on the seed transport vectors (wind, water, or animals; see Table 3). At the scale of the forest stand, RM3 is certainly the slowest, and the process of dispersal may continue for several decades after a fire [26]. 


\subsubsection{Hindering and Supporting Factors}

The main condition for this RM to be effective is the existence of forest patches that have survived the fire unburned, be it within or outside the fire's boundaries. These so-called "fire refugia" are vital, not only for the vegetation but also for animals, whom they offer shelter from the fire [37]. Heterogeneity of land forms, also referred to as roughness of the terrain, is a factor that increases the number of unburned patches within the fire's boundaries. Other crucial forest characteristics that foster unburned patches include heterogeneity in terms of flammability, height of cover, land use, and type of canopy [36]. At the individual level, tree height, trunk size, and bark thickness are directly correlated with survival after a fire [36].

However, the above factors progressively lose importance with increasing fire intensity: If fire intensity is high and uniform within the burn area, RM3 will be less active as the number of surviving individuals and fire refugia will be severely reduced This, in turn, depends on the type and amount of fuel and on the environmental conditions at the time of ignition: key factors are wind speed, air humidity, and temperature.

After the fire, surviving plants have to be capable of producing seeds. As mentioned with regard to RM1, seed production may be influenced by competition; water and nutrient availability; and soil quality. Moreover, seed production is highly variable over time: external and genetic factors can trigger enormous differences from year to year [38].

Once they have been produced, seeds are then dispersed by wind, gravity, and animal vectors. Depending on the vector, environmental conditions, and their own physical characteristics, the seeds may be deposited at various distances from the parent individual. When it comes to primary dispersal, which normally occurs by wind or gravity, most studies concur that the vast majority of seeds are deposited within a radius of 20 to $50 \mathrm{~m}$, depending on the seed type, wind conditions, and height of the parent plant and landform [35].

Once the seeds are on the ground, their fate depends on the behavior of animals. Animals play an ambivalent role: they eat and damage the seeds (predation) but also transport them to new areas (secondary dispersal) [39]. Secondary dispersal of seeds by animals is crucial to the recolonization of post-fire areas. Thus, animals act as both a hindering and a supporting factor. The relative influence of predation and dispersion remains difficult to quantify [38]. Once dispersed, seeds may germinate if the microhabitat is favorable; this process is influenced by the same hindering and supporting factors as those affecting germination within RM1 (see Section 3.1.3).

\subsection{Impacts of Land Management on Resilience}

As part of our analysis of the processes that affect resilience to fire in Mediterranean forests, we identified factors that hinder or support these processes. These factors include different ecosystem components apart from the vegetation. Some of them can be influenced by management (Tables 4 and 5).

Table 4. Overview of factors hindering RMs.

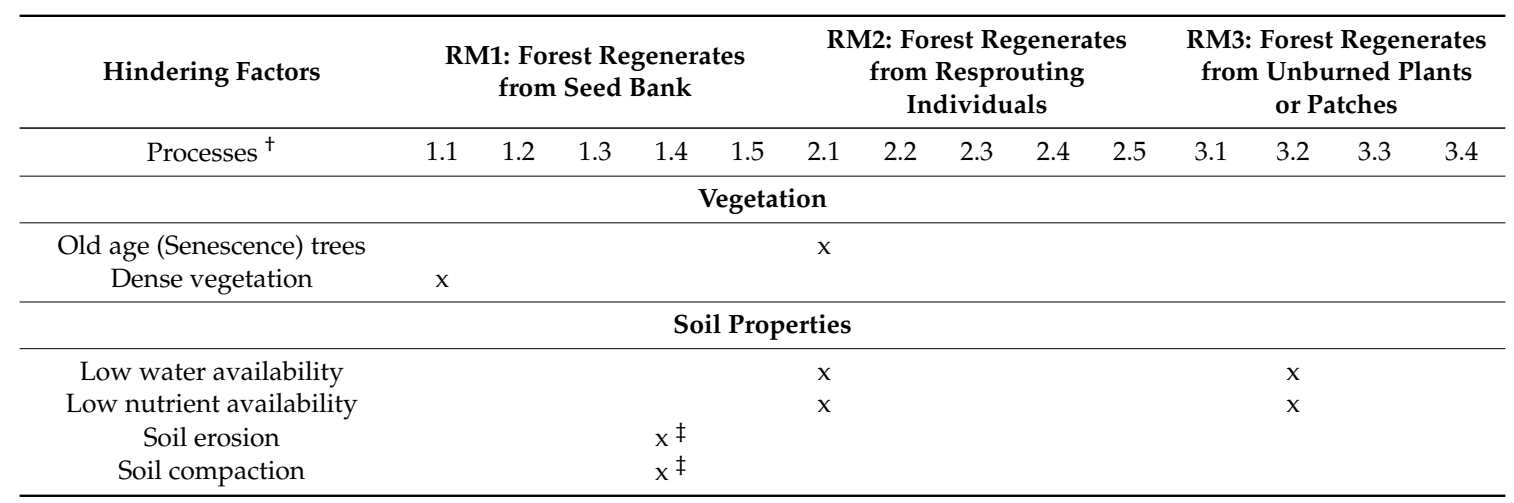


Table 4. Cont.

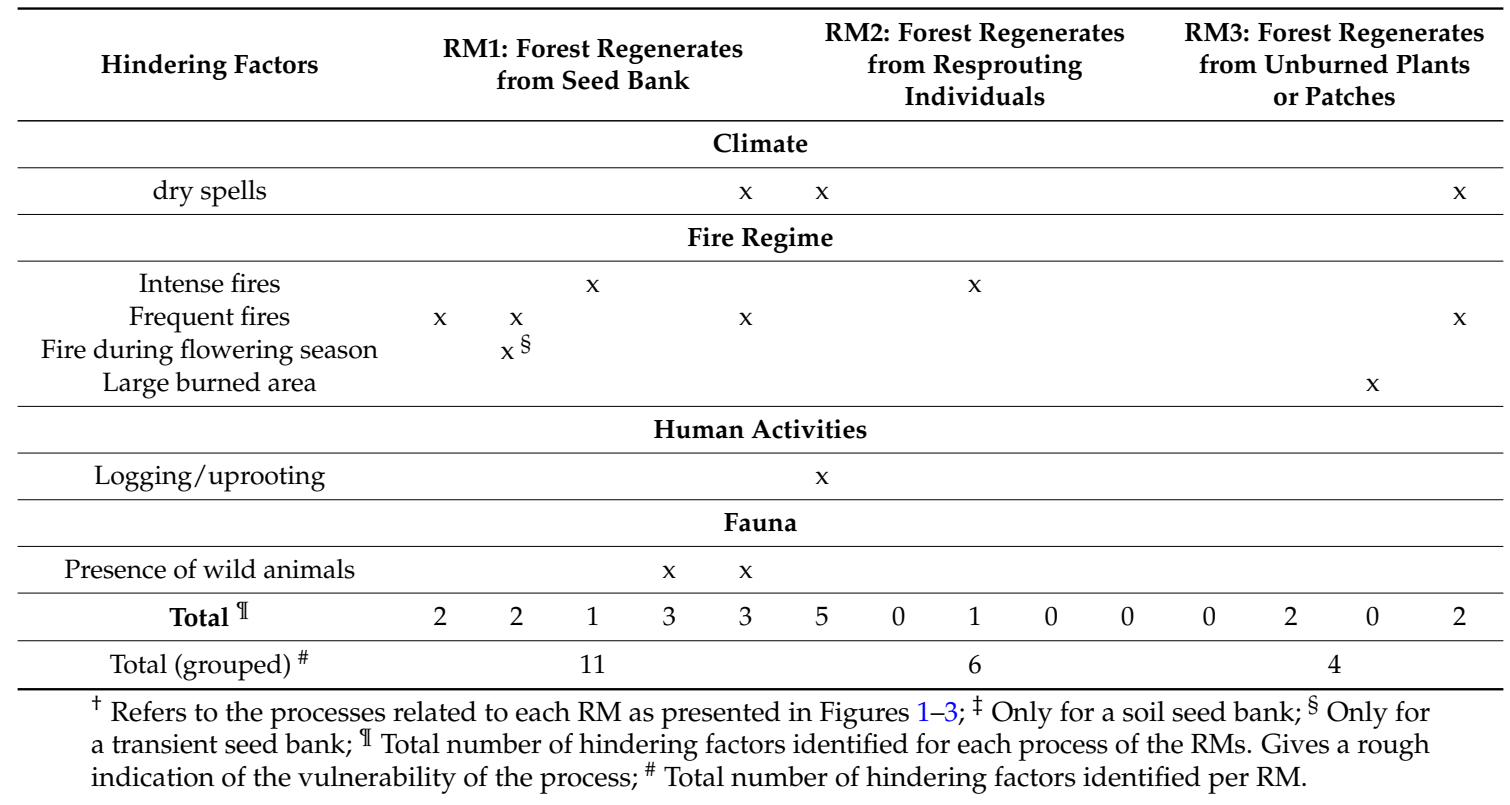

Table 5. Overview of factors supporting RMs.

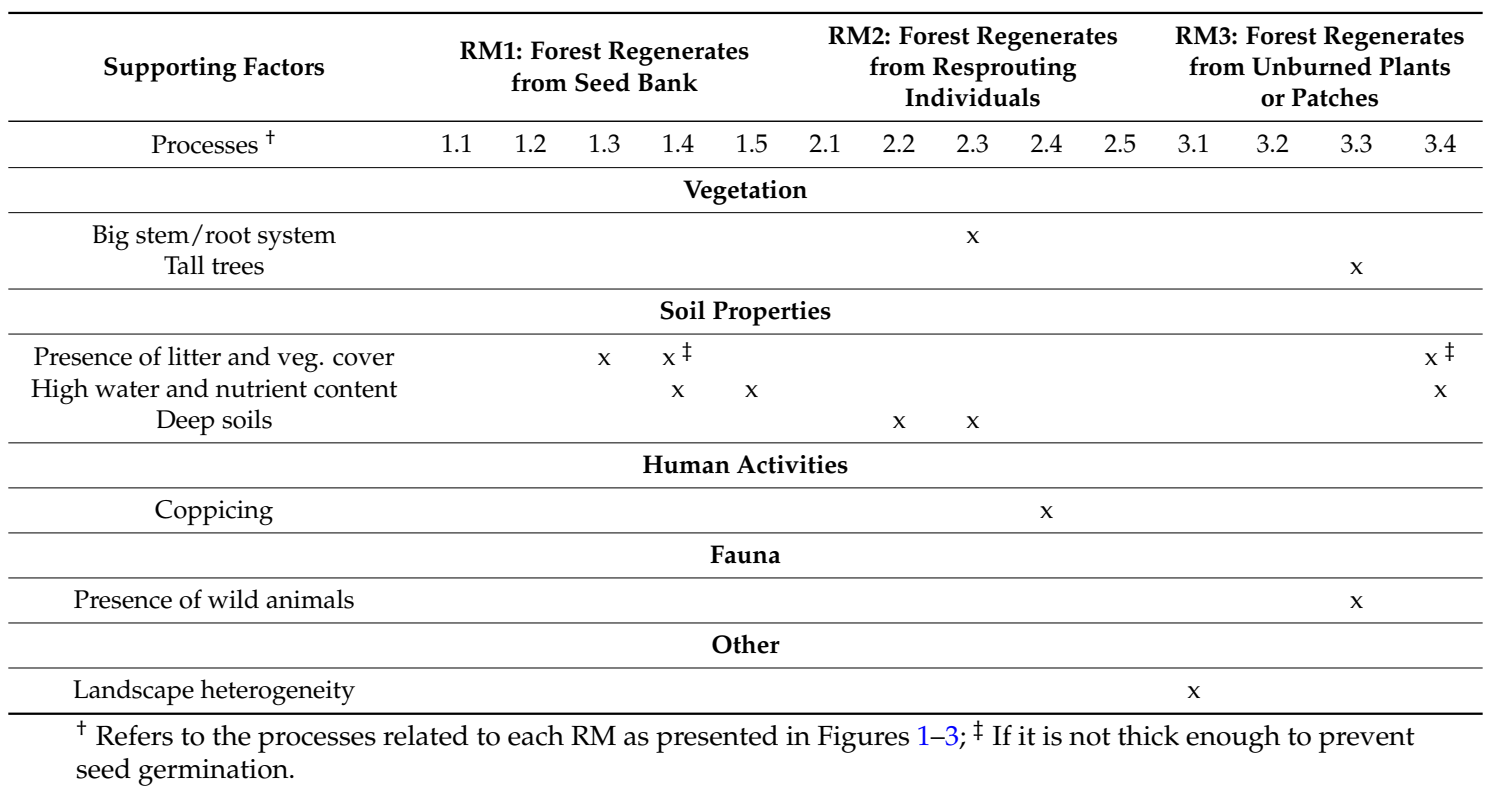

3.4.1. Relationship between WOCAT Ecological Indicators and Factors Hindering and Supporting Resilience

Nine land management practices in the WOCAT database [12] were identified as relevant for this study. They cover prevention (before the fire), fire impact mitigation, and rehabilitation (after the fire). For the purpose of the subsequent analysis we grouped them according to their objectives: (1) fuel breaks; (2) fuel management; (3) afforestation; and (4) mulching (Table 6). Three of the management practices were documented and assessed in Spain (SPA), three in Portugal (POR), two in Italy (ITA), and one in Morocco (MOR). The summary result sheet for each management practice referenced in Table 6 is available as Supplementary Material. 
Table 6. Land management practices for Mediterranean forests from the WOCAT technology database, categorized according to their objective.

\begin{tabular}{cl}
\hline WOCAT Code & \multicolumn{1}{c}{ Technology Name } \\
\hline & \multicolumn{1}{c}{ 1. Fuel Breaks (Prevention) } \\
\hline POR001 & Primary strip network system for fuel management \\
SPA009 & Cleared strip network for fire prevention (fuel breaks) \\
ITA007 & Unvegetated strips to reduce fire expansion \\
\hline & 2. Fuel Management (Prevention) \\
\hline POR002 & Prescribed fire \\
SPA010 & Selective forest clearing to prevent large forest fires \\
ITA008 & Selective cutting \\
\hline & 3. Reforestation (Rehabilitation) \\
\hline SPA012 & Afforestation with Pinus halepensis after the fire of 1979 \\
MOR013 & Assisted cork oak regeneration \\
\hline & 4. Soil Protection (Mitigation) \\
\hline POR003 & Post-fire forest residue mulch \\
\hline
\end{tabular}

Among other information, the WOCAT assessment method includes an evaluation of the technology based on indicators of benefits and disadvantages. Many of these can be related to the hindering and supporting factors identified for the three RMs. Figure 4 provides an overview of these relations.

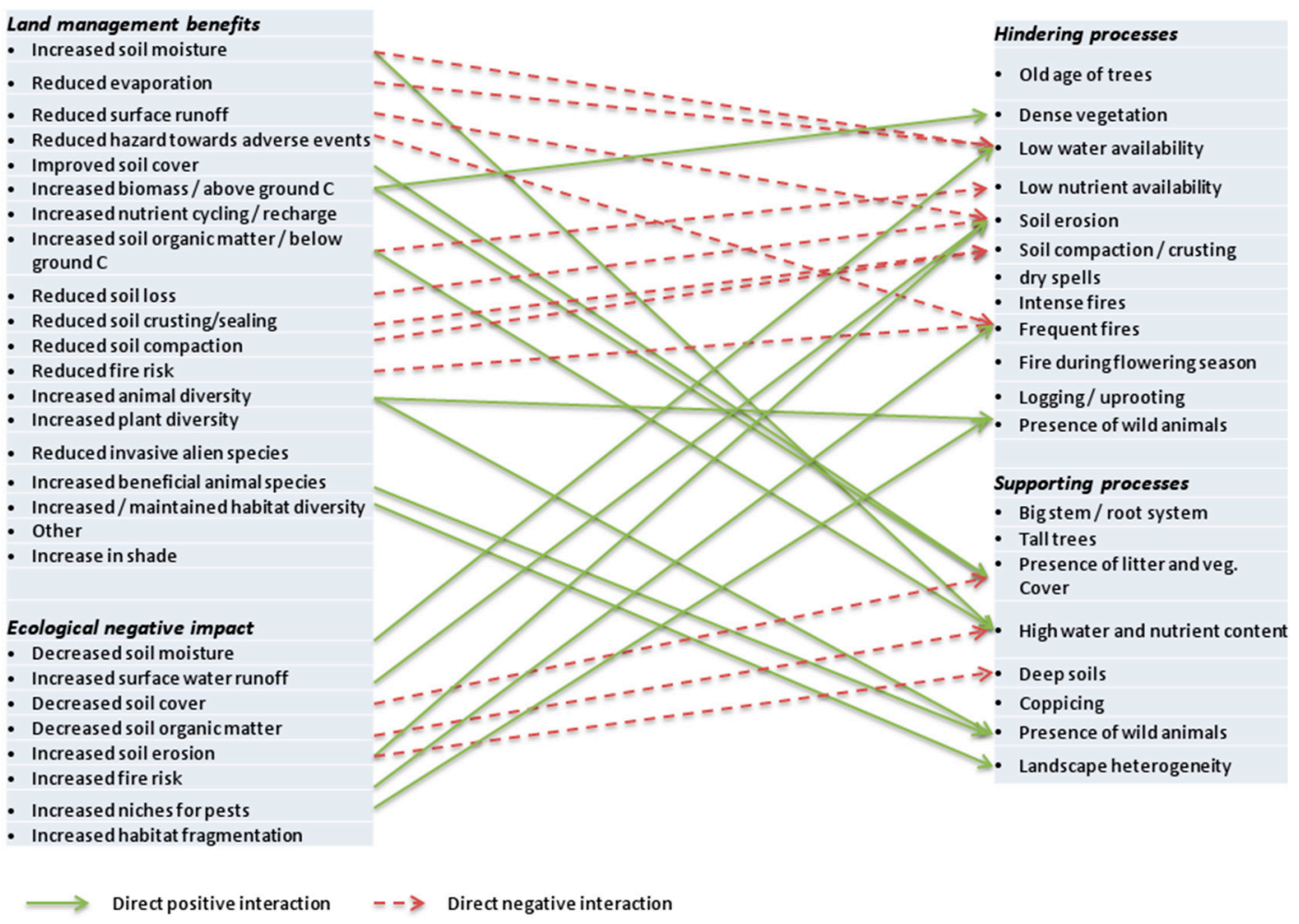

Figure 4. Direct relations between WOCAT indicators of ecological benefits and disadvantages (left) (Source: WOCAT technology questionnaire, Section 3.1.1 [12]) and hindering and supporting factors of resilience (right). Solid arrows represent direct positive (reinforcing) relations; dashed arrows represent a negative relationship. The full matrix of relations, including also indirect relations, is part of Appendix A. 
In the following subsections, we present the four groups of land management options and assess how their ecological indicators relate to the factors hindering and supporting each regeneration mechanism. In doing so, we identify hindering and supporting interactions between land management practices and resilience.

\subsubsection{Fuel Breaks}

Fuel breaks are linear features within the forest where the vegetation has been removed. Their placement depends on the slope, location of roads, and average wind direction. They are probably the most common management practice and are often the first staple in national programmes to reduce the risk of fire [40]. Researchers and technical experts stress that fuel breaks not only help prevent fires from spreading, but also make it easier to access areas and conduct interventions during a fire event [5].

Fuel breaks are implemented in networks over large areas of forest. Resulting forest structures are characterized by wide forest areas interspersed with linear discontinuities of varying width. Thus, fuel breaks have a limited effect on the forest structure as a whole [41].

Reported aims of this land management practice are to reduce forest continuity and the area potentially affected by fire (SPA), to slow down the progress of fire (ITA), to provide access and increase safety for fire fighters during interventions (SPA, ITA, POR), and to protect roads, infrastructure, and areas of special value (POR). In the case of large fuel breaks, their central part is cleared to the mineral soil, while adjacent areas are left with an increasing density of vegetation (SPA, POR), with a selection of the biggest and most fire-resistant species (SPA).

The main benefit of fuel breaks, as assessed with the WOCAT methodology, is the reduction of fire risk (SPA, ITA, POR). Disadvantages include decreased soil cover (SPA, POR), increased surface water runoff (SPA, POR), decreased soil organic matter (SPA, POR), increased soil erosion (SPA, POR), and increased habitat fragmentation (SPA) (see Table 7). The decrease in soil cover and soil organic matter, as well as the increase in runoff only affect the area actually occupied by the fuel break and have no relevant impact on the surrounding forested area (see Table 7, "Average value").

Table 7. Benefits and disadvantages of fuel breaks as assessed with the WOCAT technology questionnaire.

\begin{tabular}{cccc}
\hline \multicolumn{2}{c}{ Benefits of Fuel Breaks } & \multicolumn{2}{c}{ Disadvantages of Fuel Breaks } \\
\hline Indicator & Average Value $^{\dagger}$ & Indicator & Average Value $^{\dagger}$ \\
\hline reduced hazard towards adverse events & 2.7 & increased surface water runoff & 1.0 \\
reduced fire risk & 2.7 & decreased soil cover & 1.5 \\
& & decreased soil organic matter & 1.0 \\
& & increased soil erosion (locally) & 1.0 \\
& & increased habitat fragmentation & 1.0 \\
\hline
\end{tabular}

${ }^{\dagger}$ Values are attributed on a scale from 1 (Low) to 3 (High) for each management practice.

Figure 5 gives an overview of supporting and hindering interactions between fuel breaks and the three RMs. As shown in Section 3.1.3, fire frequency is a major hindering factor for RM1. By limiting the spread of fire, fuel breaks reduce the number of fires occurring in a specific area, thus increasing the likelihood of plants reaching maturity [40,41]. This is shown as interactions (a) and (d) in Figure 5. Fuel breaks might indirectly reduce the occurrence of fires in spring or autumn, thereby increasing the probability of a healthy seed bank existing at the moment of fire (b). The negative impacts of fuel breaks on soil (increased erosion, runoff, decreased cover, decreased organic matter: see Table 7) could decrease germination rate, either on the fuel break itself or in its proximity (c).

Fuel breaks have no relevant effect on RM2, as they do not affect fire intensity, and local soil conditions have no impact on resprouting trees outside the fuel break area. If selective cutting is applied at the margins of the fuel break, this could increase the average size of plants and the presence of resprouters (e) [42]. The only potential negative effect might occur if fire were excluded permanently 
from the area, as this would enable resprouter plants to reach senescence age and lose their resprouting capacity (see Section 3.2.3) (f).

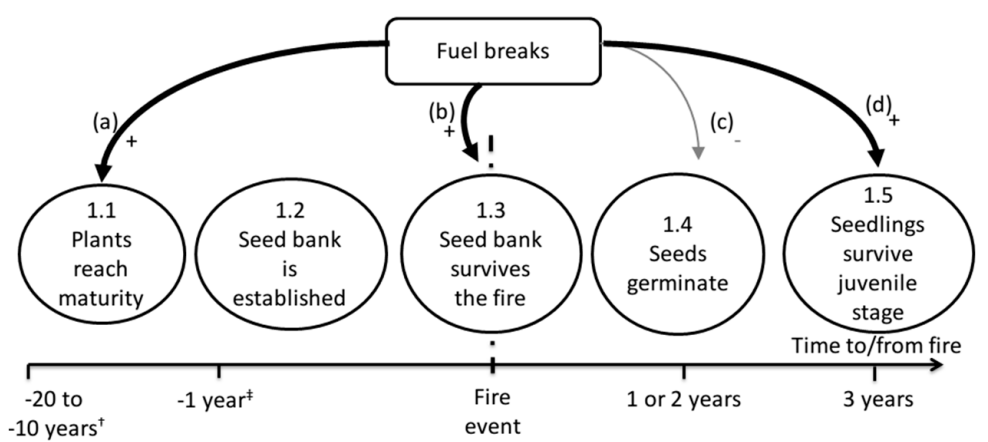

(A)

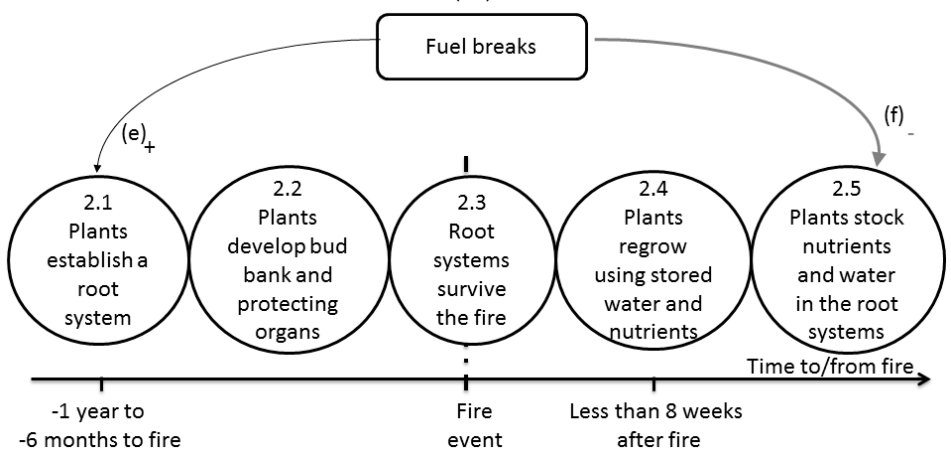

(B)

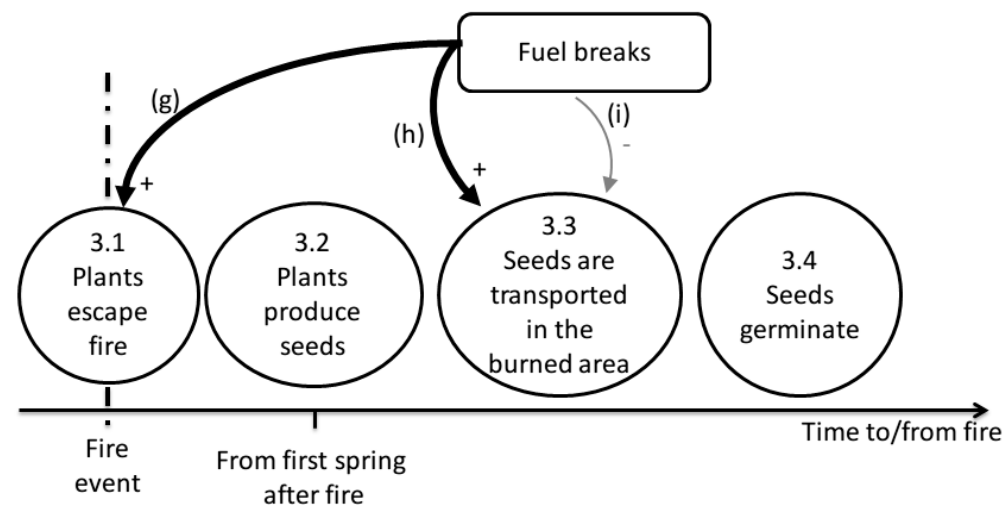

(C)

Figure 5. Impact of fuel breaks on the resilience of Mediterranean forest to fire. (A) Impact of fuel breaks on RM1; (B) Impact of fuel breaks on RM2; (C) Impact of fuel breaks on RM3. The width of arrows indicates the relative importance of supporting $(+)$ and hindering $(-)$ interactions.

The size of the burned area and canopy continuity are major hindering factors for RM3, as they affect the number of patches that survive the fire unburned and the probability of seeds reaching the burned area. By reducing both factors, fuel breaks play an important role in ensuring the effectiveness of the RM $(\mathrm{g}, \mathrm{h})[42]$. However, fuel breaks of the largest category, whose total width may reach up to $90 \mathrm{~m}$ (SPA, POR), may act as an ecological barrier to recolonization, and increase the possibility of alien species proliferation, hindering forest resilience through RM3 [43] (k).

\subsubsection{Fuel Management}

One of the ways to reduce fire risk is by removing part of the flammable material from the forest. This can be dead material, the understory, or selected individuals (e.g., fire-prone species and senescent 
or ill plants). It may even involve temporary total removal of the canopy, as in prescribed burning. This group of forest management practices, while having the same objective, is indeed very diverse in effects and measures. Selective clearing is the more labour-intensive option, which not only enables modification of the fuel load, but also modification of species composition and the structure of the forest stand. Depending on the type of forest, it can involve removal of seedlings and young trees to facilitate the development of bigger, less flammable trees; it can also include pruning the lower branches of the trees in order to reduce the possibility of fire spreading from the ground to the tree-level canopy. Prescribed burning does not allow for direct selection of material for removal, and it includes risks of losing proper control and generating a wildfire. Moreover, many researchers stress the negative impacts of prescribed burning on soils, but debate over the trade-offs of this management practice remains ongoing [44].

Reported objectives include reducing the amount of fuel present in the area (SPA, POR, ITA), creating or increasing discontinuity in the canopy (SPA, POR), preventing the spread of alien species and pests (SPA, POR), and changing canopy composition to include more fire-resistant species or increase diversity (SPA, POR). Fuel management can be achieved through prescribed burning (POR), cutting and removal of vegetation (SPA), or cutting and chipping of wood which is then used as mulch (SPA, ITA).

Relevant benefits of these management practices are: reduced wildfire risk (ITA, SPA, POR), increased biological pest/disease control (POR), and increased habitat diversity (SPA, POR). In the case of selective cutting, benefits also include a reduction in alien/invasive species (POR). Further benefits occur if the wood is chipped and dispersed on site as mulch: among others, the proportion of soil covered by litter increases, nutrients are recharged, soil moisture increases, and soil crusting or sealing is reduced (SPA). Negative impacts of fuel management technologies include increased soil erosion, decreased soil cover and organic matter (if mulching is not applied), and increased habitat fragmentation (Table 8).

Table 8. Benefits and disadvantages of the fuel management practices.

\begin{tabular}{|c|c|c|c|}
\hline \multicolumn{2}{|l|}{ Benefits of Fuel Management } & \multicolumn{2}{|c|}{ Disadvantages of Fuel Management } \\
\hline Indicator & $\begin{array}{l}\text { Average } \\
\text { Value }\end{array}$ & Indicator & $\begin{array}{c}\text { Average } \\
\text { Value }\end{array}$ \\
\hline increased soil moisture & 3 & increased surface water runoff & 1 \\
\hline reduced evaporation & 1 & decreased soil cover $\ddagger$ & 1.5 \\
\hline reduced hazard towards adverse events & 2.5 & decreased soil organic matter & 1 \\
\hline improved soil cover & $1^{+}$ & increased soil erosion (locally) & 1 \\
\hline increased biomass/above ground C & 1.5 & increased habitat fragmentation & 1 \\
\hline increased nutrient cycling/recharge & 1 & & \\
\hline increased soil organic matter/below ground C & 1 & & \\
\hline reduced soil crusting/sealing & 1 & & \\
\hline reduced fire risk & 3 & & \\
\hline increased animal diversity & 1 & & \\
\hline reduced invasive alien species & 3 & & \\
\hline increased/maintained habitat diversity & 3 & & \\
\hline reduced soil surface temp & 1 & & \\
\hline
\end{tabular}

${ }^{\dagger}$ If mulching is applied, otherwise there is an increase in bare soil; ${ }^{\ddagger}$ Only if mulching is not applied.

The impacts of fuel management on the three RMs are shown in Figure 6. Looking at RM1, a reduction in fuel decreases fire intensity, with a positive impact on seed bank survival [42] (a). However, if fuel management is implemented through prescribed burning, it will have a negative impact on the soil [45], resulting in a reduced germination rate (b). Positive impacts on RM1 further include reduced vegetation density, leading to reduced competition and hence increased probability of seedlings reaching maturity and producing seeds. Mulching increases soil fertility and seed sheltering, and most likely leads to an increase in the germination rate (c) [46], if the mulch layer is not too thick. 


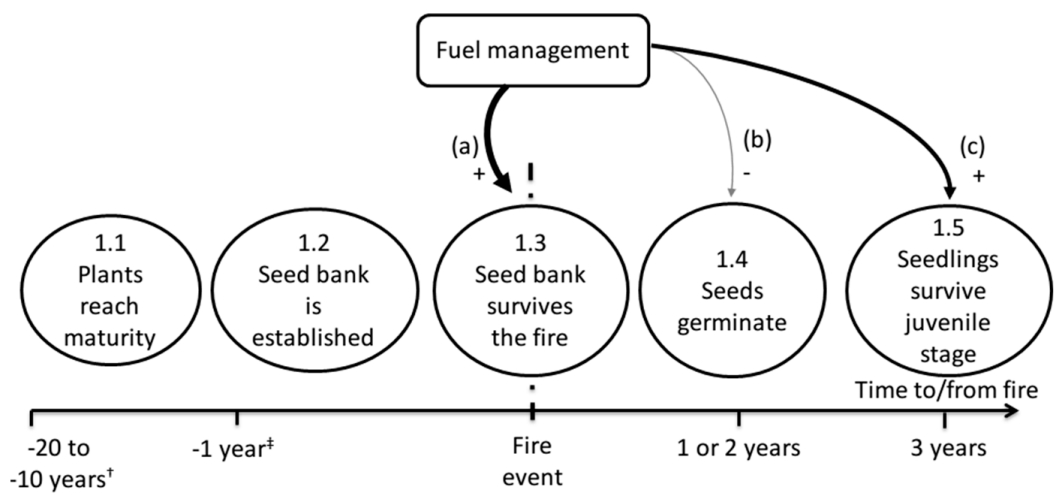

(A)

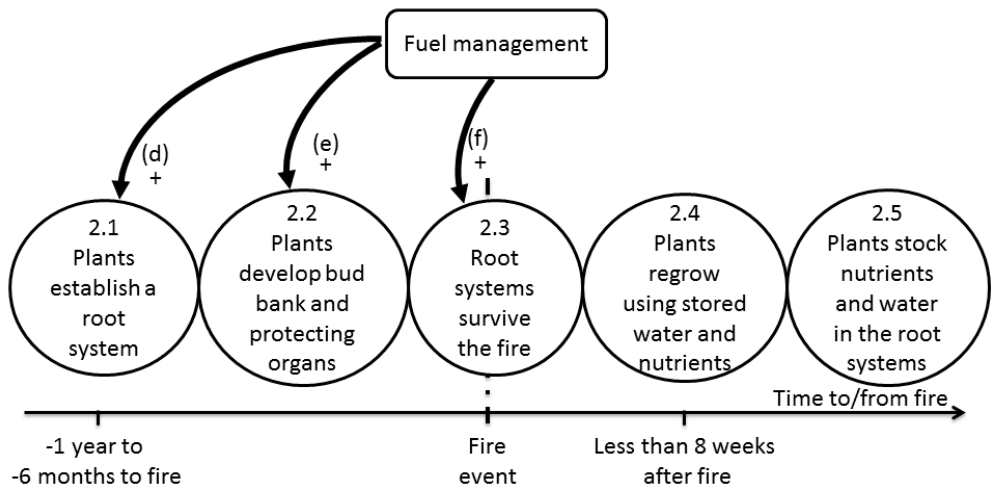

(B)

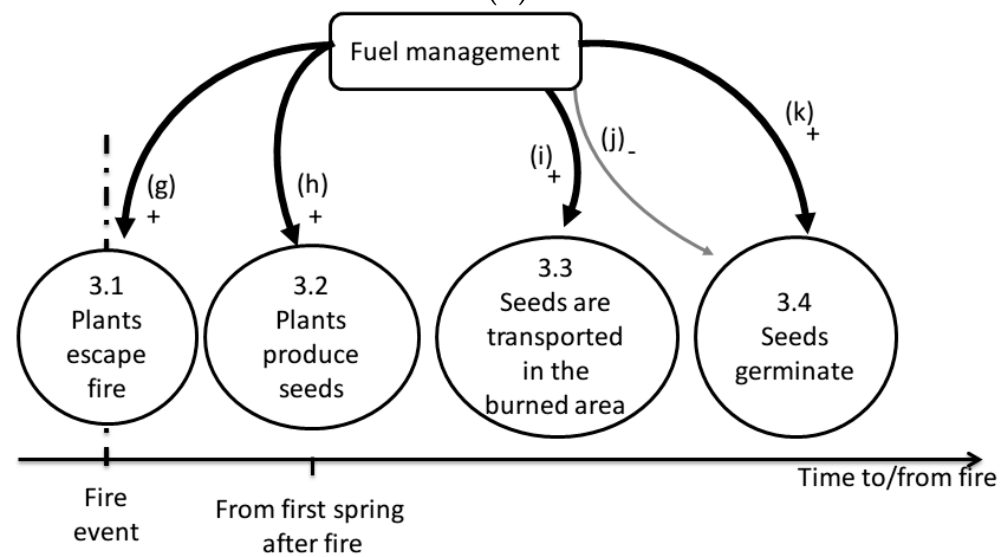

(C)

Figure 6. Impact of fuel management on the resilience of Mediterranean forest to fire: (A) Impacts on RM1; (B) Impacts on RM2; (C) Impacts on RM3. The width of arrows indicates the relative importance of supporting $(+)$ and hindering $(-)$ interactions.

Resprouter species, which use RM2, benefit above all from reduced competition with seeder species before the fire, increasing their chances of survival and their resprouting vigour (d); this applies to both selective clearing and prescribed burning. In the case of selective clearing, the most fire-prone species are usually cut, allowing more fire-resistant species such as Quercus, Juniperus, and Fraxinus species to grow in size, increasing their chances of surviving and resprouting after a fire (SPA) (e). Improved soil and moisture conditions from mulching might improve conditions for recruitment of resprouter species, which are generally much more demanding than seeders in terms of water and nutrients [47] and are favored by gaps within the understory (see Section 3.2.1) (f).

Reduction of fire intensity is crucial to RM3, as it increases the chances of individuals and patches surviving a fire unburned and acting as sources of forest regeneration [5] (g). This positive effect is 
even more important if the healthiest and largest individuals are left in place during selective clearing, as this leads to increased survival as well as increased seed production and dispersal after the fire (h). Clearing of understory through prescribed fire can result in an increase in highly palatable grasses, leading to increased animal presence and potentially to increased seed dispersal [48] (i). As in the case of RM1, fuel reduction might lead to an increase in soil erosion that can reduce the germination rate and seedling survival by diminishing soil fertility (j). However, this negative interaction can be countered by applying mulching, which improves soil fertility and reduces fire-related degradation (k).

Aside from the direct ecological impact of fuel management, the wood gathered from fuel management operations can be sold, and gains reinvested, in management measures [49]. This applies in particular to selective forest clearing (ITA, SPA), where increased wood production was reported as a socio-economic benefit.

\subsubsection{Afforestation}

Direct planting of trees is applied when natural regeneration fails. The aim is to restore the canopy and increase the soil cover; the planted vegetation is expected to gradually develop into a secondary forest. The management practices documented in the WOCAT database used Pinus halepensis (SPA) or Quercus ilex (MOR).

These management practices are common in forest areas that have failed to regenerate or have been otherwise deforested. Pinus spp. or other seeder species are used because of their high growth rate and ability to withstand low availability of essential resources. However, resulting forests tend to have lower species diversity and very dense, homogeneous canopies that present a high risk of fire. Researchers have highlighted the negative impacts of this practice [50], stressing the importance of using a broader mix of species [5]. In some management plans, restoration projects include a second afforestation phase that introduces resprouters (e.g., Quercus ilex, Q. faginea) in the pine afforestation, thereby reducing the risk of fire and increasing the diversity of the forest stand.

Afforestation with Cork Oak (MOR) follows this latter idea, thereby increasing the benefits of the management in the long term. However, Quercus ilex seedlings are much more vulnerable to drought, which is why water has to be provided through an irrigation system. Moreover, growth is much slower compared to Pinus, leading to reduced benefits in the short term.

The technique used to plant the trees is important, as it affects the soil and the remnant vegetation. For the Pinus afforestation (SPA), machinery was used to create an individual hole for each seedling; seedlings were then planted by hand. In the assisted Cork Oak regeneration, land managers dug straight furrows able to hold a row of multiple seedlings. Reported benefits mainly relate to the soil and include increased soil cover, increased soil moisture, reduced runoff, and reduced soil crusting. Reported disadvantages include a heightened fire risk and an increase in niches for pests (Table 9).

Table 9. Benefits and disadvantages of afforestation.

\begin{tabular}{cccc}
\hline \multicolumn{2}{c}{ Benefits of Afforestation } & \multicolumn{2}{c}{ Disadvantages of Afforestation } \\
\hline Indicator & $\begin{array}{c}\text { Average } \\
\text { Value }\end{array}$ & Indicator & $\begin{array}{c}\text { Average } \\
\text { Value }\end{array}$ \\
\hline increased soil moisture & 2.5 & increased fire risk $^{+}$ & 2.0 \\
reduced evaporation & 1 & increased niches for pests (birds, slugs, rodents, etc.) & 2.0 \\
reduced surface runoff & 2.5 & & \\
improved soil cover & 2 & & \\
increased biomass/above ground C & 2 & & \\
increased nutrient cycling/recharge & 2 & & \\
increased soil organic matter & 2 & & \\
reduced soil loss & 2.5 & & \\
reduced soil crusting/sealing & 1.5 & \\
increased animal diversity & 1.5 & \\
increased plant diversity & 1 &
\end{tabular}


Figure 7 provides an overview of how afforestation influences the RMs. For RM1, increasing the number of seeder individuals might be expected to have a positive effect on forest resilience to fire via a larger seed bank (a). However, many seeder trees, including Pinus halepensis, are highly flammable, so afforestation based on such species greatly increases the amount of fuel and the risk of fire [50]. Flammability of Cork Oak is instead much lower. If the time between two fires is too short for the plants to reach sexual maturity, a subsequent fire can cause total failure of afforestation. However, even without such a catastrophic shift, afforestation with Pinus halepensis may have an adverse effect on resilience to fire: its seeds are dispersed by fire, so after a fire the new canopy could become extremely dense, reducing seedling growth and further development of the canopy.

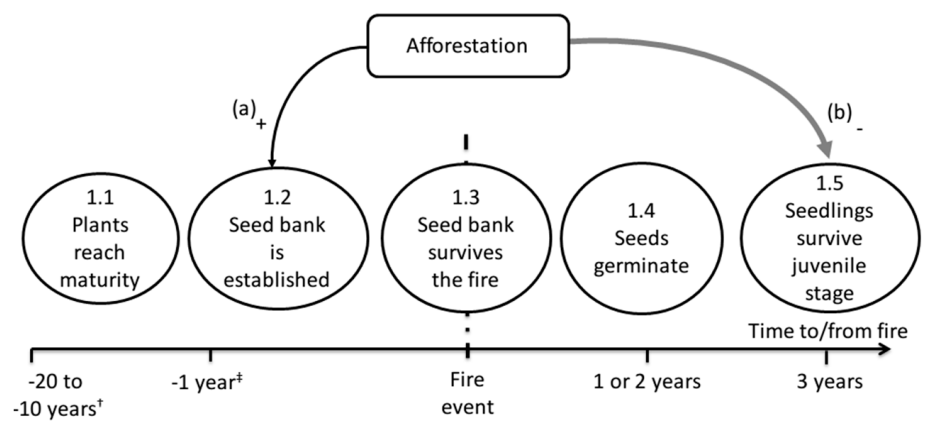

(A)

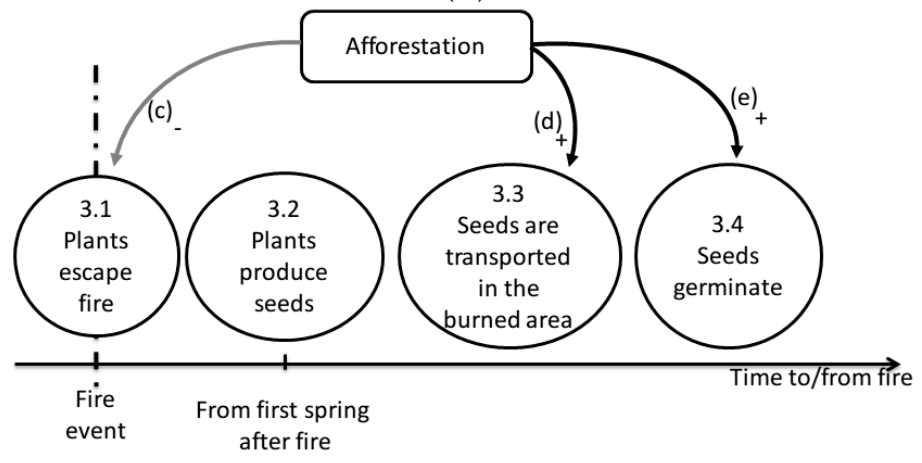

(B)

Figure 7. Impact of afforestation on the resilience of Mediterranean forest to fire: (A) Impacts on RM1; (B) Impacts on RM2. The width of arrows indicates the relative importance of supporting (+) and hindering $(-)$ interactions.

Plants that use RM2 are not affected by fire frequency and are often shade-tolerant, so afforestation should have no negative impact on these resprouters as long as they are not killed during afforestation work. However, areas chosen for afforestation do not normally have a high tree presence, and even less of resprouting individuals. For this reason, we cannot establish a direct link between afforestation with Pinus halepensis and RM2.

Planted trees tend to form a homogeneous, continuous canopy, reducing the chances of patches escaping a fire [47] and potentially increasing the size of the burned area (c). However, increased soil moisture, nutrient content, and soil stability may promote post-fire recruitment (e). Moreover, the reported increase in animal diversity might lead to greater secondary dispersion (d).

\subsubsection{Post-Fire Mulching}

Post-fire mulching consists of spreading chopped forest residues on slopes after a fire to increase the ground cover and reduce erosion and increase water infiltration (Figure 8). This greatly reduces post-fire degradation. Fires of high intensity will consume pre-fire litter; leaves and branches left over after the fire will not suffice to effectively protect the soil, leaving it exposed to weathering and 
erosion by water. Mulching is applied on steep slopes, where fire intensity tends to be high, and uphill from infrastructure or valuable areas. It is best carried out immediately after the fire, before the next rain. Relevant benefits of mulching include increased soil cover, reduced soil loss, reduced surface runoff, and decreased evaporation. No disadvantages were reported for this technology in the WOCAT assessment.

Figure 9 gives an overview of the impacts of mulching on forest resilience to fire. As explained in Section 3.1.3, the presence of litter or covering material is crucial for seeds to survive until germination, as it reduces decay, erosion, and animal predation [51] (a). Furthermore, by helping to maintain soil humidity and soil organic matter content, it promotes the recovery of soil fauna and nutrient cycling after the fire. All these factors contribute to greater soil fertility, which in turn increases the germination rate and seedling survival [46] (c). Accordingly, mulching is clearly beneficial to RM1. However, if mulching is too thick, it can decrease the germination rate of obligate seeder species such as Ulex parviflorus or Cistus sp. (b).

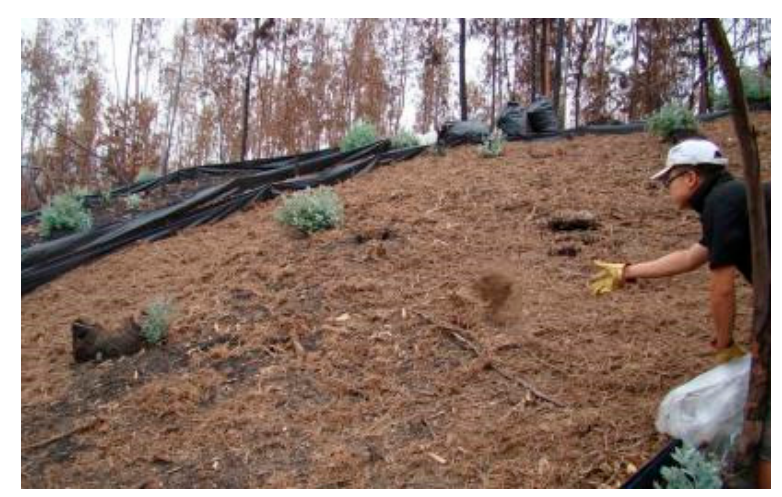

Figure 8. Spreading of natural mulch on a burned steep slope. Source: WOCAT T_POR003en, “Post-fire residue mulch", compiled by Sergio Prats.

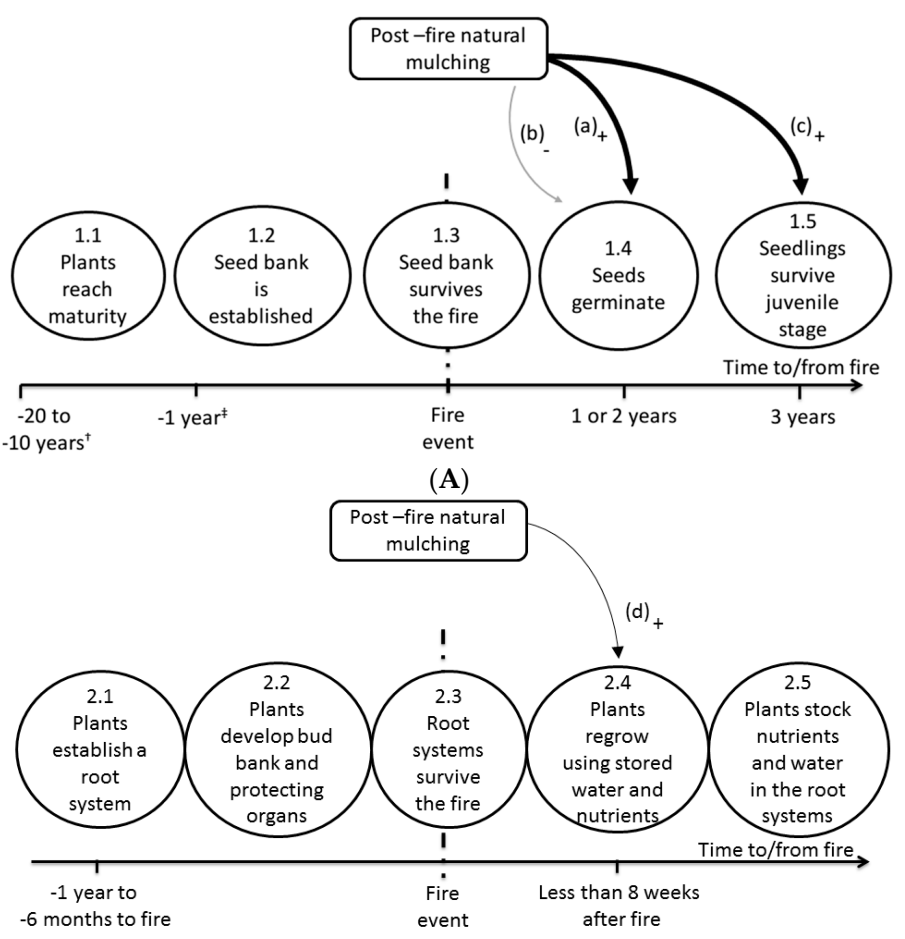

(B)

Figure 9. Cont. 


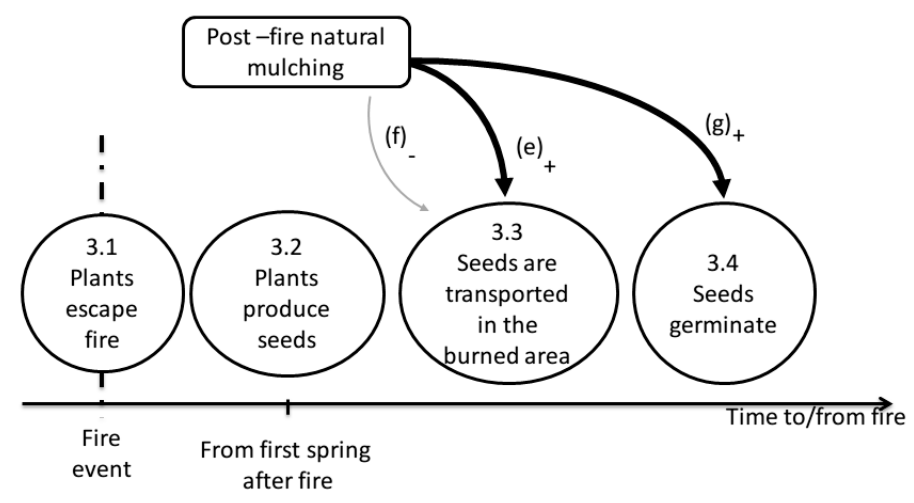

(C)

Figure 9. Impact of mulching on the resilience of Mediterranean forest to fire: (A) Impacts on RM1; (B) Impacts on RM2; (C) Impacts on RM3. The width of arrows indicates the relative importance of supporting (+) and hindering (-) interactions.

Post-fire soil conditions have no major impact on RM2, as resprouter plants maintain their own reserves of nutrients and water. However, greater soil humidity after a fire may promote resprouting, thereby increasing the speed of regeneration $(\mathrm{d})$.

Seed survival and germination are important processes in RM3. Accordingly, the presence of continuous litter and stable, humid soil is important in enabling recruitment (e) and seedling survival (g). Germination could also be hindered by a thick layer of mulch (f).

\section{Discussion}

\subsection{RMs}

The concept of RMs elaborated in this paper bears similarity to concepts used by ecologists to study plant traits related to fire (e.g., concept of "regeneration paths" by Pausas and Keeley [13]). However, fire ecologists focus mainly on how fires affect plant evolution and morphology, as well as on how individual plants adapt to fire disturbances $[14,25,52]$. While these studies are fundamental to improving our understanding of the ecosystem, they rarely provide useful recommendations for management, as they do not take into account environmental factors that might influence a fire event and post-fire recovery, nor of the interactions that occur at a larger scale. Our review of the literature on forest ecology and post-fire forest regeneration reveals two important aspects of forest resilience: First, there are various processes that are important to post-fire regeneration that may take place before the fire event. Thus, efforts to increase forests' resilience to fire should be launched prior to fires, not only after the event. Second, there are a number of processes that play a role in post-fire forest regeneration that are not directly related to the fire event itself. These processes are often poorly understood in light of their effects on post-fire regeneration. Moreover, there is a need for research on the relative significance of these processes and on important thresholds that can influence regeneration. Further, we lack quantitative indications regarding thresholds in the various processes constituting RMs.

\subsection{Can We Increase Forest Resilience through Land Management?}

Mediterranean forests are composed of various species, and land managers cannot choose which of the three RMs their system will follow. However, by examining its species composition and monitoring the hindering and supporting factors, they can understand which RM is most likely to fail or function. Depending on their management practices, the fire regime, and other environmental factors, they can focus their attention on those processes that are at risk of failing.

RM1-forest regeneration from seed banks-requires the longest interval between fires (see Section 3.1.2) and has the most hindering factors (Table 4). However, our analysis of the impact of 
management practices indicates that fuel breaks and fuel management might considerably increase the resilience of plants using this mechanism.

In contrast, RM2 - forest regeneration from resprouting individuals-appears to be the most stable of the three mechanisms, the quickest to foster recovery, and the least influenced by external factors (Table 4). It has to be noted, however, that the establishment of resprouter species is difficult, and can be hindered by many factors (see Table 4, "Total"). The management practices analyzed do not seem to have any relevant influence on it, with the exception of fuel management through selective clearing (see Section 4.3).

RM3-forest regeneration from unburned plants-contrary to the other processes, does not require any preparation period prior to the fire event, and is therefore independent of the frequency of fires. It is the slowest way for a forest to recover, and the one that is most likely to bring changes to the system. The impacts of management on this RM are the most uncertain, mainly due to the high number of processes involved and the paucity of scientific knowledge about it.

When comparing the management practices, fuel management appears to increase forest resilience the most. It is especially beneficial to pre-fire processes, which makes it a strategic option for prevention. Afforestation with Pinus halepensis seems the least promising of all management practices; this becomes even more so if we consider the high cost of implementation and the low success rate in terms of seedling survival and fire risk at the long term. Fuel management and afforestation can be implemented in very different ways, and the specific implementation technique strongly affects how these practices influence RMs.

The available literature on forest management $[53,54]$ generally supports the information provided by the WOCAT database, as well as the conclusions drawn in this article.

In particular, researchers have highlighted the importance of fuel management to reduce the risk and spreading of fire [53]. Through adequate species and age selection, and taking into account the landscape, this practice also increases the resilience of forest stands in the long term [55]. Furthermore, fuel management can be combined with logging so that economic exploitation of the forest and resilience increase can both be achieved [56].

Studies have shown that post-fire mulching is effective in reducing soil erosion and is beneficial to regrowth [46]. However, while no disadvantages where reported in the WOCAT assessment, researchers have stressed the risk of spreading invasive species, if the material used for mulching is not accurately selected and prepared [57].

While most management practices have been studied for their effect on fire regimes, and some (e.g., fuel management and afforestation) also with regard to post-fire recovery, very few empirical studies have analysed the diverse impacts of management on soil erosion, seed bank establishment, and other factors involved in the resilience of Mediterranean forests to fire. In light of these gaps, despite WOCAT's largely qualitative and somewhat general approach to assessing management practices, the WOCAT database represents an important tool for use in better understanding the role of forest management. Moreover, both the literature review and the land management practice assessment are mostly related to Mediterranean Europe. Additional efforts should be made to increase the information available on Mediterranean North Africa.

\subsection{Other Factors Influencing Forests' Resilience to Fire}

Focusing on regeneration makes it possible to directly relate impacts of land management to forest resilience. However, there are other factors that can increase the resilience of forests and improve the likelihood of post-fire regeneration: First, certain land uses, in particular grazing and wood gathering, reduce the amount of available fuel in forests, thus reducing the risk of repeated and intense fire. These activities were part of forest use for centuries, and their disappearance-owing to declining (perceived) economic returns-is an important factor in the changing of fire regimes of many Mediterranean countries. However, these activities also implied in some cases the removal of root systems, reducing or even eliminating completely the presence of keystone resprouting species. Second, 
the shape and diversity of landscape mosaics have direct effects on fire spreading, fire suppression, and post-fire regeneration (especially vis-à-vis RMs). The interplay between forest areas, open areas (e.g., pastures), and areas with low flammability (e.g., orchards, built areas) influences the size and occurrence of burned areas following a fire. In many forest stands of the Mediterranean Basin, land abandonment is radically changing the traditionally diverse and patchy landscapes, with clear effects on fire regimes and forest evolution. Third, the presence of certain plants or combinations of plants has beneficial impacts on soils and ecosystems in general. Increasing research on functional groups, and clear identification of the most important ones, will undoubtedly improve land managers' ability to enhance the resilience of forest stands.

\section{Conclusions}

We have investigated the literature related to the recovery of forest after fire using the concept of Regeneration Mechanisms (RMs) defined as the chains of processes that allow the forest to recover after a fire event, and we have been able to characterize the time frame and the hindering and supporting factors of 3 different RMs: (1) from seeds that survived the fire; (2) from resprouting individuals; and (3) from unburned plants. This framework proved useful to summarize the scientific knowledge about resilience in dry Mediterranean forest and to investigate the role of land management, and could be applied to other ecosystems and geographical areas.

Forest regeneration from seed banks requires the longest interval between fires and has the most hindering factors, but our analysis indicates that land management, in particular fuel breaks and fuel management, can widely increase its effectiveness. Forest regeneration from resprouting individuals appears to be the most stable of the three mechanisms, the quickest to foster recovery, and the least influenced by external factors. Regeneration from unburned individuals is the only RM that is independent from fire frequency, but many aspects of it are still unclear and would need further research.

The results of our study stress the importance of the processes that take place before the fire event. Thus, efforts to increase forests' resilience to fire should be launched prior to fires, not only after the event. Moreover, the regeneration of forest after a fire does not depend only on the frequency of intensity of fires, but is related to the type, age, and development of the plant; soil conditions; and climatic conditions before and after a fire. Land managers should take into account these factors if they want to increase forest resilience to fire.

Among the land management practices analyzed, fuel management appears to increase forest resilience the most. It is especially beneficial to pre-fire processes, which makes it a strategic option for prevention. Afforestation with seeder species appears to be the least beneficial for resilience increase and the practice with the most uncertain results.

Supplementary Materials: The following are available online at www.mdpi.com/2071-1050/8/10/981/s1. Summary results of the WOCAT assessment for selected land management practices available at: https://dl.dropboxusercontent.com/u/26249349/ResMechanisms-LMPractice.pdf.

Acknowledgments: This paper was developed within the CASCADE project (Seventh Framework Programme (FP7/2007-2013) under grant agreement 283068). The authors acknowledge financial support from the CASCADE project and the European Cooperation in Science and Technology (COST) action ES1104 "Arid Lands Restoration and Combat of Desertification". We also thank the contributors to the WOCAT database: Nina Lauterburg (CDE), Celeste Coelho and Sergio Prats (University of Aveiro, Portugal), and Velia de Paola (University of Basilicata, Italy). In addition, we would like to thank Jaime Baeza for his help in sharpening the concepts and his insights on fire ecology. The authors thank Marlène Thibault and Tina Hirschbuehl (CDE) for the language editing. Thanks also go to the editor and the anonymous reviewers for their comments and suggestions, which enabled significant improvements to the manuscript.

Author Contributions: Matteo Jucker Riva framed the paper idea and wrote the paper; Hanspeter Liniger and Gudrun Schwilch structured the analysis of the land management practice; Alejandro Valdecantos contributed to the analysis of the ecological literature.

Conflicts of Interest: The authors declare no conflict of interest. The founding sponsors had no role in the design of the study; in the collection, analyses, or interpretation of data; in the writing of the manuscript; and in the decision to publish the results. 
Appendix A. Matrix of Interactions between Ecological Benefits and Disadvantages of Land Management Practices and Factors Hindering or Supporting Forest Resilience

Appendix A.1. Interactions between Ecological Benefits of Land Management and Factors Supporting or Hindering Land Forest Resilience

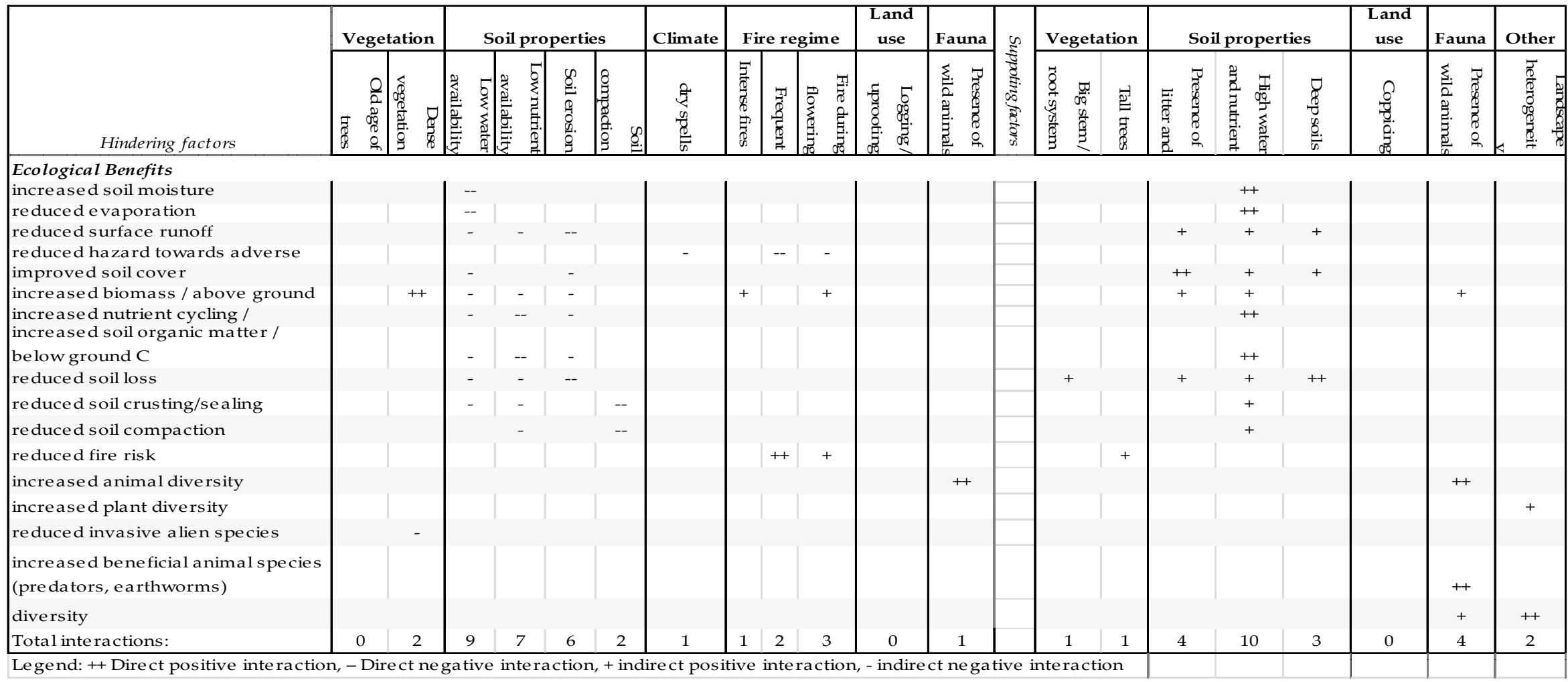

Figure A1. Matrix of interactions between ecological benefits of land management practices and factors hindering or supporting forest resilience. 
Appendix A.2. Interactions between Ecological Disadvantages of Land Management and Factors Supporting or Hindering Land Forest Resilience

\begin{tabular}{|c|c|c|c|c|c|c|c|c|c|c|c|c|c|c|c|c|c|c|c|c|c|}
\hline \multirow[b]{2}{*}{ Hindering factors } & \multicolumn{2}{|c|}{ Vegetation } & \multicolumn{4}{|c|}{ Soil properties } & \multirow{2}{*}{\begin{tabular}{|c|} 
Climate \\
\\
\\
\\
\\
\\
$\frac{8}{4}$ \\
$\frac{0}{0}$ \\
$\frac{0}{\infty}$ \\
\end{tabular}} & \multicolumn{3}{|c|}{ Fire regime } & \multirow{2}{*}{ 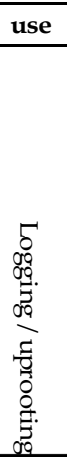 } & \multirow{2}{*}{ 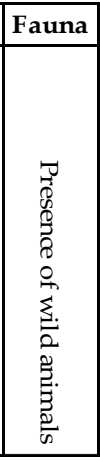 } & \multirow[b]{2}{*}{ 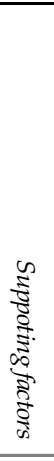 } & \multicolumn{2}{|c|}{ Vegetation } & \multicolumn{3}{|c|}{ Soil properties } & \multirow{2}{*}{ 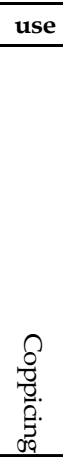 } & \multirow{2}{*}{ 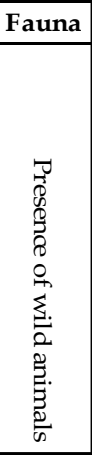 } & \multirow{2}{*}{ 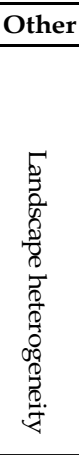 } \\
\hline & 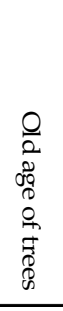 & 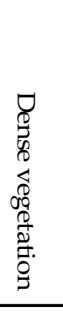 & 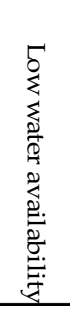 & 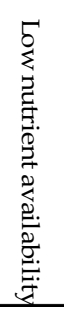 & $\begin{array}{l}\text { \&. } \\
0.0 \\
8 \\
0 \\
0 . \\
0 \\
\end{array}$ & 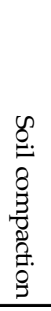 & & 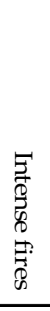 & 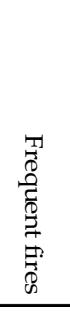 & 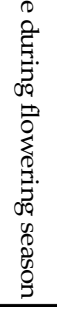 & & & & 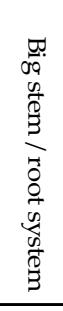 & 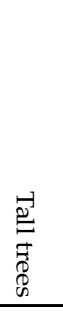 & 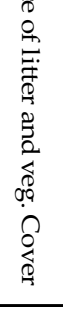 & 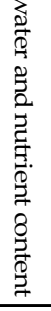 & 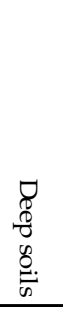 & & & \\
\hline \multicolumn{22}{|c|}{ Ecological negative impacts } \\
\hline $\begin{array}{l}\text { decreased soil } \\
\text { moisture }\end{array}$ & & & ++ & + & & & & + & & & & & & & & & -- & & & & \\
\hline $\begin{array}{l}\text { increased surface } \\
\text { water runoff }\end{array}$ & & & + & + & ++ & & & & & & & & & & & + & + & + & & & \\
\hline $\begin{array}{l}\text { decreased soil } \\
\text { cover }\end{array}$ & & & + & + & + & & & & & & & & & & & -- & - & - & & & \\
\hline $\begin{array}{l}\text { decreased soil } \\
\text { organic matter }\end{array}$ & & & ++ & ++ & + & + & & & & & & & & - & & & -- & & & & \\
\hline $\begin{array}{l}\text { increased soil } \\
\text { erosion (locally) }\end{array}$ & & & & + & ++ & & & & & & & & & - & & - & - & -- & & & \\
\hline increased fire risk & & & & & & & & & ++ & + & & & & & & & & & & & \\
\hline $\begin{array}{l}\text { increased niches for } \\
\text { pests }\end{array}$ & & & & & & & & & & & & ++ & & & & & & & & - & \\
\hline $\begin{array}{l}\text { increased habitat } \\
\text { fragmentation }\end{array}$ & & & & & & & & & & & & + & & & & & & & & & - \\
\hline Total interactions: & 2 & 1 & 7 & 6 & 5 & 2 & 2 & 3 & 2 & 2 & 2 & 4 & & 4 & 1 & 5 & 6 & 4 & 2 & 3 & 3 \\
\hline
\end{tabular}

Legend: ++ Direct positive interaction, - Direct negative interaction, + indirect positive interaction, - indirect negative interaction

Figure A2. Matrix of interactions between ecological disadvantages of land management practices and factors hindering or supporting forest resilience. 


\section{References}

1. Pausas, J.G.; Llovet, J.; Rodrigo, A.; Vallejo, R. Are wildfires a disaster in the Mediterranean basin? A review. Int. J. Wildland Fire 2008, 17, 713-723. [CrossRef]

2. Santana, V.M.; Alday, J.G.; Baeza, M.J. Effects of fire regime shift in Mediterranean Basin ecosystems: Changes in soil seed bank composition among functional types. Plant Ecol. 2014, 215, 555-566. [CrossRef]

3. Peterson, G.; Allen, C.R.; Holling, C.S. Ecological Resilience, Biodiversity, and Scale. Ecosystems 1998, 1, 6-18. [CrossRef]

4. Buma, B.; Wessman, C.A. Disturbance interactions can impact resilience mechanisms of forests. Ecosphere 2011, 2, 64. [CrossRef]

5. Reinhardt, E.D.; Keane, R.E.; Calkin, D.E.; Cohen, J.D. Objectives and considerations for wildland fuel treatment in forested ecosystems of the interior western United States. For. Ecol. Manag. 2008, 256, 1997-2006. [CrossRef]

6. Paula, S.; Arianoutsou, M.; Kazanis, D. Fire-related traits for plant species of the Mediterranean Basin. Ecology 2009, 90. [CrossRef]

7. Lavorel, S. Ecological diversity and resilience of Mediterranean vegetation to disturbance. Divers. Distrib. 1999, 5, 3-13. [CrossRef]

8. Ferran, A.; Delitti, W.; Vallejo, V.R. Effects of fire recurrence in Quercus coccifera L. shrublands of the Valencia Region (Spain): II. Plant and soil nutrients. Plant Ecol. 2005, 177, 71-83. [CrossRef]

9. Liniger, H.; Schwilch, G. Enhanced Decision-Making Based on Local Knowledge. Mt. Res. Dev. 2002, 22, 14-18. [CrossRef]

10. Schwilch, G.; Bestelmeyer, B.; Bunning, S.; Critchley, W.; Herrick, J.; Kellner, K.; Liniger, H.P.; Nachtergaele, F.; Ritsema, C.J.; Schuster, B.; et al. Experiences in monitoring and assessment of sustainable land management. Land Degrad. Dev. 2011, 22, 214-225. [CrossRef]

11. World Overivew of Approaches and Tehcnologies Technology Database. Available online: https://qt.wocat.net/ (accessed on 30 April 2014).

12. WOCAT. Questionnaire on SLM Technologies (Basic). A Framework for the Evaluation of Sustainable Land Management Practices (Revised); Liniger, H., Schwilch, G., Gurtner, M., Studer Mekdaschi, R., Hauert, C., van Lynden, G., Critchley, W., Eds.; Centre for Development and Environment, Institute of Geography, University of Bern: Bern, Switzerland, 2008.

13. Pausas, J.G.; Keeley, J.E. Evolutionary ecology of resprouting and seeding in fire-prone ecosystems. New Phytol. 2014, 204, 55-65. [CrossRef] [PubMed]

14. Buhk, C.; Meyn, A.; Jentsch, A. The challenge of plant regeneration after fire in the Mediterranean Basin: Scientific gaps in our knowledge on plant strategies and evolution of traits. Plant Ecol. 2007, 192, 1-19. [CrossRef]

15. Verdú, M. Ecological and evolutionary differences between Mediterranean seeders and resprouters. J. Veg. Sci. 2000, 11, 265-268. [CrossRef]

16. Truţa, E.; Capraru, G.; Surdu, Ş.; Zamfirache, M.M.; Olteanu, Z.; Roşu, C.M.; Oprica, L. Karyotypic studies in ecotypes of Hippophaë rhamnoides L. from Romania. Silvae Genet. 2010, 59, 175-182.

17. Spanos, I.A.; Daskalakou, E.N.; Thanos, C.A. Postfire, natural regeneration of Pinus brutia forests in Thasos island, Greece. Acta Oecol. 2000, 21, 13-20. [CrossRef]

18. Hackett, W.P. Juvenility and maturity. Cell Tissue Cult. For. 1987, 24-26, 216-231.

19. Long, R.L.; Gorecki, M.J.; Renton, M.; Scott, J.K.; Colville, L.; Goggin, D.E.; Commander, L.E.; Westcott, D.A.; Cherry, H.; Finch-Savage, W.E. The ecophysiology of seed persistence: A mechanistic view of the journey to germination or demise. Biol. Rev. 2015, 90, 31-59. [CrossRef] [PubMed]

20. Quintana, J.R.; Cruz, A.; Fernández-González, F.; Moreno, J.M. Time of germination and establishment success after fire of three obligate seeders in a Mediterranean shrubland of central Spain. J. Biogeogr. 2004, 31, 241-249. [CrossRef]

21. Hanley, M.E.; Fenner, M. Pre-germination temperature and the survivorship and onward growth of Mediterranean fire-following plant species. Acta Oecol. 1998, 19, 181-187. [CrossRef]

22. Keeley, J.E. Fire intensity, fire severity and burn severity: A brief review and suggested usage. Int. J. Wildland Fire 2009, 18, 116-126. [CrossRef] 
23. Vallejo, V.R.; Arianoutsou, M.; Moreira, F. Post-Fire Management and Restoration of Southern European Forests; Moreira, F., Arianoutsou, M., Corona, P., De las Heras, J., Eds.; Springer: Dordrecht, The Netherlands, 2012.

24. Saracino, A.; D'Alessandro, C.M.; Borghetti, M. Seed colour and post-fire bird predation in a Mediterranean pine forest. Acta Oecol. 2004, 26, 191-196. [CrossRef]

25. Bond, W.J.; Midgley, J.J.; Bond, W.J.; Midgley, J.J. 2001_Bond_Trend in Ecol and Evo_Ecology of sprouting in woody plants the persistence niche. Trends Ecol. Evol. 2001, 16, 45-51. [CrossRef]

26. Rodrigo, A.; Retana, J.; Picó, F.X. Direct regeneration is not the only response of Mediterranean forests to large fires. Ecology 2004, 85, 716-729. [CrossRef]

27. Romano, A.; Barros, S.; Martins-Loução, M.A. Micropropagation of the Mediterranean tree Ceratonia siliqua. Plant Cell. Tissue Organ Cult. 2002, 68, 35-41. [CrossRef]

28. Ojeda, F.; Brun, F.G.; Vergara, J.J. Fire, rain and the selection of seeder and resprouter life-histories in fire-recruiting, woody plants. New Phytol. 2005, 168, 155-165. [CrossRef] [PubMed]

29. Clarke, P.J.; Lawes, M.J.; Midgley, J.J.; Lamont, B.B.; Ojeda, F.; Burrows, G.E.; Enright, N.J.; Knox, K.J.E. Resprouting as a key functional trait: How buds, protection and resources drive persistence after fire. New Phytol. 2013, 197, 19-35. [CrossRef] [PubMed]

30. Hodgkinson, K.C. Sprouting success of shrubs after fire: Height-dependent relationships for different strategies. Oecologia 1998, 115, 64-72. [CrossRef]

31. Malanson, G.P.; Trabaud, L.; Malanson, G.P.; Trabaud, L.; Emberger, L. Vigour of Post-Fire Resprouting by Quercus Coccifera L. J. Ecol. 2013, 76, 351-365. [CrossRef]

32. Canadell, J.; Lloret, F.; López-Soria, L. Resprouting vigour of two mediterranean shrub species after experimental fire treatments. Vegetatio 1991, 95, 119-126.

33. López-Soria, L.; Castell, C. Comparative genet survival after fire in woody Mediterranean species. Oecologia 1992, 91, 493-499. [CrossRef]

34. Barberis, A.; Dettori, S.; Filigheddu, M.R. Management problems in Mediterranean cork oak forests: Post-fire recovery. J. Arid Environ. 2003, 54, 565-569. [CrossRef]

35. Tavşanoğlu, Ç.; Gürkan, B. Long-term post-fire dynamics of co-occurring woody species in Pinus brutia forests: The role of regeneration mode. Plant Ecol. 2014, 215, 1-11. [CrossRef]

36. Román-Cuesta, R.M.; Gracia, M.; Retana, J. Factors influencing the formation of unburned forest islands within the perimeter of a large forest fire. For. Ecol. Manag. 2009, 258, 71-80. [CrossRef]

37. Radford, I.J.; Andersen, A.N.; Graham, G.; Trauernicht, C. The fire refuge value of patches of a fire-sensitive tree in fire-prone savannas: Callitris intratropica in northern Australia. Biotropica 2013, 45, 594-601. [CrossRef]

38. Nathan, R.; Muller-Landau, H.C. Spatial patterns of seed dispersal, their determinants and consequences for recruitment. Trends Ecol. Evol. 2000, 15, 278-285. [CrossRef]

39. Vander Wall, S.B.; Kuhn, K.M.; Beck, M.J. Seed removal, seed predation, and secondary dispersal. Ecology 2005, 86, 801-806. [CrossRef]

40. Green, L. Fuelbreaks and Other Fuel Modification for Wildland Fire Control. 1977. Available online: http://www.fs.fed.us/psw/publications/documents/usda_series/usda_ah499.pdf (accessed on 23 September 2016).

41. Finney, M.A. Design of regular landscape fuel treatment patterns for modifying fire growth and behavior. For. Sci. 2001, 47, 219-228.

42. Baeza, M.J.; Raventós, J.; Escarré, A.; Vallejo, V.R. The effect of shrub clearing on the control of the fire-prone species Ulex parviflorus. For. Ecol. Manag. 2003, 186, 47-59. [CrossRef]

43. Merriam, K.E.; Keeley, J.E.; Beyers, J.L. Fuel breaks affect nonnative species abundance in Californian plant communities. Ecol. Appl. 2006, 16, 515-527. [CrossRef]

44. Fernandes, P.M.; Davies, G.M.; Ascoli, D.; Fernández, C.; Moreira, F.; Rigolot, E.; Stoof, C.R.; Vega, J.A.; Molina, D. Prescribed burning in southern Europe: Developing fire management in a dynamic landscape. Front. Ecol. Environ. 2013, 11, e4-e14. [CrossRef]

45. Debano, L.F. The role of fire and soil heating on water repellency in wildland environments: A review. J. Hydrol. 2000, 231-232, 195-206. [CrossRef]

46. Bautista, S.; Bellot, J.; Vallejo, V.R. Mulching treatment for postfire soil conservation in a semiarid ecosystem. Arid Soil Res. Rehabil. 1996, 10, 235-242. [CrossRef]

47. Khurana, E.; Singh, J.S. Ecology of seed and seedling growth for conservation and restoration of tropical dry forest: A review. Environ. Conserv. 2001, 28, 39-52. [CrossRef] 
48. Arevalo, J.R.; Fernandez-Lugo, S.; Garcia-Dominguez, C.; Naranjo-Cigala, A.; Grillo, F.; Calvo, L. Prescribed burning and clear-cutting effects on understory vegetation in a Pinus canariensis stand (Gran Canaria). Sci. World J. 2014, 2014, 215418. [CrossRef] [PubMed]

49. Vélez, R. Fire Effects and Fuel Management in Mediterranean Ecosystems in Spain. 1982. Available online: http://www.southernregion.fs.fed.us/psw/publications/documents/psw_gtr058/psw_ gtr058_6a_velez.pdf (accessed on 23 September 2016).

50. Maestre, F.T.; Cortina, J. Are Pinus halepensis plantations useful as a restoration tool in semiarid Mediterranean areas? For. Ecol. Manag. 2004, 198, 303-317. [CrossRef]

51. Pérez-Ramos, I.M.; Marañón, T. Factors affecting post-dispersal seed predation in two coexisting oak species: Microhabitat, burial and exclusion of large herbivores. For. Ecol. Manag. 2008, 255, 3506-3514. [CrossRef]

52. Naturalist, T.A.; de Donana, E.B. Historical effects and sorting processes as explanations for contemporary ecological patterns: Character syndromes in mediterranean woody plants. Am. Nat. 1992, 140, 421-446.

53. Agee, J.K.; Skinner, C.N. Basic principles of forest fuel reduction treatments. For. Ecol. Manag. 2005, 211, 83-96. [CrossRef]

54. Valdecantos, A.; Baeza, M.J.; Vallejo, V.R. Vegetation management for promoting ecosystem resilience in fire-prone mediterranean shrublands. Restor. Ecol. 2009, 17, 414-421. [CrossRef]

55. Moya, D.; De Las Heras, J.; López-Serrano, F.R.; Leone, V. A post-fire management model to improve Aleppo pine forest resilience. In WIT Transactions on Ecology and the Environment; WIT PRESS, Ashurst Lodge: Ashurst, UK, 2008; Volume 119, pp. 311-319.

56. Ferreira, L.; Constantino, M.; Borges, J.G. A stochastic approach to optimize Maritime pine (Pinus pinaster Ait.) stand management scheduling under fire risk. An application in Portugal. Ann. Oper. Res. 2014, 219, 359-377. [CrossRef]

57. Kruse, R.; Bend, E.; Bierzychudek, P. Native plant regeneration and introduction of non-natives following post-fire rehabilitation with straw mulch and barley seeding. For. Ecol. Manag. 2004, 196, 299-310. [CrossRef]

(C) 2016 by the authors; licensee MDPI, Basel, Switzerland. This article is an open access article distributed under the terms and conditions of the Creative Commons Attribution (CC-BY) license (http://creativecommons.org/licenses/by/4.0/). 